\title{
Fabrication of Cerium Titanate Cellulose Fiber Nanocomposite Materials for the Removal of Methyl Orange and Methylene Blue from Polluted Water by Photocatalytic Degradation
}

yousra kotp ( $\nabla$ yoso20002000@yahoo.com )

Desert Research Center

Research Article

Keywords: Cerium titanate (Ce-Ti), Cellulose fiber (Cf), Photocatalytic degradation, Sunflower seed husk, dyes

Posted Date: February 4th, 2022

DOI: https://doi.org/10.21203/rs.3.rs-1162307/v1

License: (c) (1) This work is licensed under a Creative Commons Attribution 4.0 International License. Read Full License 
Fabrication of Cerium Titanate Cellulose Fiber Nanocomposite Materials for the Removal of Methyl Orange and Methylene Blue from Polluted Water by Photocatalytic Degradation

Yousra H. Kotp

Water Treatment \& Desalination Unit, Hydrogeochemistry Department, Desert Research Center, El-Matariya, Cairo, P.O.B 11753, Egypt.

Corresponding author. Tel.: +2 01063953608; fax: +2 0226389069. E-mail address: yoso20002000@yahoo.com

\section{Abstract}

Green synthesis is anenvironmentally responsible, simple, and emerging approach to nanoparticle synthesis (NPs) and currently attracts researchersworldwide. In this study, a novel (cerium titanate (Ce-Ti) and cellulose fiber (Cf) nanocomposite photocatalyst) was successfully fabricated using a crosslinking reaction between cellulose fiber (Cf) and a different molar ratio of cerium titanate (Ce-Ti) nanoparticles. The $\mathrm{Cf}$ and $\mathrm{Ce}-\mathrm{Ti}$ NPs were prepared from sunflower seed husk and its extract, respectively, through a green biosynthesis approach.Using Fourier Transform Infra-Red (FT-IR) spectroscopy, X-Ray Diffraction (XRD), and Scanning Electron Microscopy (SEM-EDX), all fabricated nanocomposites were characterized. Results obtained from the FT-IR and EDX analyses indicated that $\mathrm{Cf}$, and its composites (0.1 Ce-Ti/Cf, 0.3 Ce-Ti/Cf, and 0.5 Ce-Ti/Cf) were prepared successfully using harnessing the biomass filtrate of sunflower seed husk.

Furthermore, XRD revealed that/ the degree of crystallinity of the nanocomposites increased with the increasing molar ratios of the Ce-Ti NPs. Additionally, the photocatalytic activity of $0.1 \mathrm{Ce}-\mathrm{Ti} / \mathrm{Cf}, 0.3 \mathrm{Ce}-\mathrm{Ti} / \mathrm{Cf}$, and $0.5 \mathrm{Ce}-\mathrm{Ti} / \mathrm{Cf}$ nanocomposite samples in the presence and absence of hydrogen peroxide were accomplished for methylene blue (MB) and methyl orange(MO) dyes. In addition, high photodegradation efficiency was obtained by increasing the ratio of $\mathrm{TiO}_{2}$ in $\mathrm{Ce}-\mathrm{Ti}$ in the nanocomposite formula; the $\%$ degradation of methylene blue dye (MB) and methyl orange (MO) using $0.5 \mathrm{Ce}-\mathrm{Ti} / \mathrm{Cf}$ nanocomposite photocatalyst in the absence of hydrogen peroxide was 95.4 and $92.7 \%$ after 300 min, respectively. Nevertheless, with hydrogen peroxide, the \% degradation was $98.9 \%$ and $94 \%$ after $120 \mathrm{~min}$, respectively, after sunlight irradiation. Therefore, $0.1 \mathrm{Ce}-\mathrm{Ti} / \mathrm{Cf}, 0.3 \mathrm{Ce}-\mathrm{Ti} / \mathrm{Cf}$, and $0.5 \mathrm{Ce}$-Ti/Cf nanocomposite photocatalyst can be viewed as a promising material for dye wastewater treatment because of its good photocatalytic activity. Moreover, the fabricated 
nanocomposite photocatalyst acts as a promising applicant in treating wastewater collected from Egypt.

\section{Keywords:}

Cerium titanate (Ce-Ti); Cellulose fiber (Cf); Photocatalytic degradation; Sunflower seed husk; dyes

\section{Introduction}

Nowadays, wastewater is a seriousissuethat faces humankind because oftechnological development and population growth. The release of various wastes to the environment, such asherbicides, phenolic compounds, synthetic dyes, and detergents, has a significant impact on human life and the environment (Pirhashemi and Habibi-Yangjeh 2017). Chemical and biological treatments can be utilized to remove certain organic compounds, but their degradation by-products are not degradable and may be harmful (Aksu 2005; Yan et al. 2011; Zhang et al. 2014;Peng et al. 2016). The major organic chemicals classified according to their molecular structure are dyes, which are widely utilized in many industries, likeleather,cosmetics, plastics,textiles,rubber, paper printing, leather, paints, and plastics. Because oftheir complex structure, dyes are usually challenging to degrade. They can cause many disorders in animals and humans, such as irritation,allergies, dermatitis, and even cancer (Zhang et al. 2014; Peng et al. 2016; capanema et al. 2018). Therefore, the reusing of discharged wastewater became the main target to save the environment over the world(Pirhashemi and Habibi-Yangjeh 2017).

To minimize water pollution,various chemical and physical treatment techniques can be utilized to remove dyes. These technologies involveFenton chemical oxidation (Woo et al. 2014), electrochemical degradation (Fan et al. 2008), cation exchange membranes (Wu et al. 2008), bioremediation (Khataee et al. 2012), and photocatalysis(Jawad et al. 2015; Jawad et al., 2016). However, the performance of these methods is different, and there are disadvantages such ashigh cost, abundant toxic by-products (Cheng et al. 2020), and high energy consumption. Therefore, the photocatalytic method has the advantages of low energy consumption, environmental friendliness, and no selectivity in the degradation of different pollutants, and has attracted the attention of most researchers (Dong et al. 2015; Fagan et al. 2016).

However, semiconductor photocatalysts have recently attracted great interest because of their possible application in the detoxification of environmental pollutants(Tryk et al. 2000; Alvaro et al. 2010). In particular, the importance of using semiconductor photocatalysts to 
degrade organic pollutants has stimulated tremendous efforts in its synthesis and characterization methods, making it an integral part of photocatalysis research(Mills and Hunte 1997; Herrmann 1999; Pera-Titus et al. 2004; Mohamed et al. 2012). Among photocatalysts, titanium dioxide $\left(\mathrm{TiO}_{2}\right)$ has become a widely used semiconductor material, low price, non-toxicity, and long-term stability because of its excellent photoreactivity. The photocatalytic activity of $\mathrm{TiO}_{2}$ depends on several factors, likesurface area, crystallinity, impurities, and density of surface hydroxyl groups. $\mathrm{TiO}_{2}$ can be utilized as a photocatalyst for rutile crystal structures andanatase. The activity of the anatase phase is much higher than that of rutile (Lv et al. 2011), but it needs ultraviolet radiation to be activatedphotocatalytically. At present, the photocatalysis of titanium dioxide under visible light has aroused people's interest in the use of sunlight by harnessing it (Castaneda-Contreras et al. 2012).

Although a large number of mesoporous $\mathrm{TiO}_{2}$ powder and film applications have been reported thus far, there are still two major deficiencies that hinder catalyst efficiency: (i)Its broadband energy only allows activation in the ultraviolet region (about 3-5\% of the total solar spectrum), and (ii) the rapid recombination of photogenerated charges. One of the effectivemethods to eliminate the second deficiency in $\mathrm{TiO}_{2}$ photocatalytic activity is to modify $\mathrm{TiO}_{2}$ with various elements, especially rare earth metal ions and transition metals (Zhang et al. 2017). $\mathrm{CeO}_{2}$ heterojunction and cerium doping with $\mathrm{TiO}_{2}$ havebeen studied extensively because of low cost, abundant supply, high redox activity for $\mathrm{Ce}^{3+} / \mathrm{Ce}^{4+}$, easycreation of labile oxygen positions, and excessive mobility of major oxygen types(Touati et al.. 2016). Additionally, by reducing the bandgap, incorporation of $\mathrm{CeO}_{2}$ types into $\mathrm{TiO}_{2}$ is able to prolong the spectrum restraint from the ultraviolet to the visible range, resulting in the increased structural firmness of the pasted photocatalyst. Ce-modified $\mathrm{TiO}_{2}$ photocatalytic efficiency is dependent on ceria capacity and, by privation, interaction between the $\mathrm{Ce}$ and $\mathrm{Ti}$ oxides at the face, which makes better charge segaration and creates holes for chemical reactions (Luo et al. 2015; Bonfanti et al. 2018). The initial composition of the soldetermines the photocatalyst with different crystalline phases of $\mathrm{TiO}_{2}$ and $\mathrm{CeO}_{2}$. Mohammedi et al. intended and investigated $\mathrm{TiO}_{2}-\mathrm{CeO}_{2}$ nanocompositemembranes and fine particlesthat were utilized likea nanocomposite(Barrio et al. 2012). The inhancement of photocatalyticefficiency of this kind of catalyst is because of the interband state produced by $\mathrm{Ce}$, which is utilized as a doping factor in $\mathrm{TiO}_{2}$ (Barrio et al. 2012).

However, the use of nanoparticles as catalysts generally has disadvantages, such as stirring to avoid precipitation and difficulty in separating them from the suspension. To overcome these drawbacks, there are immobilization techniques, such as chemical vapor 
deposition (Zhang and Griffin 1997), sputtering (Sproul et al. 1997), polymer immobilization (Malynych et al. 2002), sol-gel (Brinker and Scherer 1990; Hu et al. 2008), and synthesis inside porous silica(Zhu et al. 2009). In the current work, biodegradable cellulose is selected as mechanical support to fix the nanoparticles. Cellulose is generallynatural biodegradable polymer on earth, renewable, cheep, andthroughyearly cellulose producesfrom plants of about (1012 tons), that is widely utilized to make fibers and gels (Capanema et al. 2018).Cellulose-based biodegradable or bio-adsorbents are investigatedwidely in the form of hydrogel, aerogel, particle, orfilm. Hydrogels and aerogels filter water slowly because wastewater containing dyes need to penetrate many pore walls. The membrane has a fast water filtration rate, but the adsorption capacity is inadequatebecause of its small thickness (Shao et al. 2021). To make the particles have more adsorption sites, the volume must be reduced to increase the specific surface region, making solid/liquid separationdifficult. The current biodegradable forms based on cellulose reduce their practical applications. Compared with them, biodegradable fiber materials show irreplaceable advantages in removal rate and adsorption capacity owing to their perfect solid-liquid separation performance, superior wastewater treatment performance, and fast water filtration speed(Shao et al. 2021). Single fiber production is cheaper than nano-scale fibrils and has admirable features such asimproved capacity,good dispersion behavior,biodegradability, higher crystallinity, good thermal stability, and high performance.Nowadays, manystudies on the extraction of individual fibers from different lignocellulosic biomass sources seem to explore their applications in manyeffective applications (Sanchez-Garcia et al. 2008; Reddy at al. 2014; Puttaswamy et al. 2017).

However, this interest also includes finding new sources of biomass to produce cellulosic monofilaments for large-scale applications. Therefore, sunflower husk can be a very attractive source of residual agricultural biomass for the production of individual fibers. Sunflower (Helianthus annuus) is an essential oilseed crop globally, and its production is second only to peanuts and soybeans (Byrareddy et al. 2008). The current consumption of sunflower seeds or their by-products as human food is very low and can be considered underutilized. However, its usage as animal feed is very extensive and continues to grow. Sunflower seeds are mainly utilized as snacks for humans, roasting the seeds into peanuts and chestnuts for consumption. Peeled sunflower seeds are widely included in vegetarian diets and are mainly sold in health food stores as an effective protein alternative source (Nwokolo 1996). Sunflower seeds are covered with a very fibrous shell that makes up about $15-25 \%$ of the seeds. These hooves are mainly used as litter for cattle. Because of its needle-like nature, 


\section{Experimental}

\subsection{Materials}

A small amount of sunflower husk can be added to animal feed as a source of fiber, which can damage the gastrointestinal tract. This experiment uses sunflower hulls as a supplementary fuel for coal-fired power plants (Crum et al. 1992). A preliminary study on natural sunflower hull fibers was reported in the literature, and it was found that these fibers contained about $25.7 \%$ cellulose and reducing sugars (Taha et al. 2012).

Therefore, we choose these outer shell fibers to extract cellulose fibers (Cf) from them. To our knowledge, there are no reports on the extraction of $\mathrm{Cf}$ from natural sunflower husks. In this paper, $\mathrm{Cf}$ and $\mathrm{CeO}_{2}-\mathrm{NPs}$ are manufactured using green synthesis technology. Toenhance the degradation efficiency of polluting dyes, the surface of $\mathrm{Cf}$ fibers was chemically crosslinked by the photocatalytic Ce-Ti NPs.The produced Ce-Ti/Cf nanocomposite fibers were investigated for the photodegradation of two organic dyes MO and $\mathrm{MB}$, with sunlight irradiation. The degradation of MO and MB was researched by evaluating the impacting degradation parameters like $\mathrm{pH}$ of the solution, irradiation period, and photocatalyst quantity. All these factors were explored to attain the best photodegradation conditions. Eventually, the improved nanocomposite fibers were utilized in the photodegradation processes for real polluted water gathered from Egypt.

Cellulose fibres were extracted from sunflower seed husk waste, directly collected from a local market in Egypt. All chemicals that utilized in this work were purchased from Sigma- Aldrich Co. (e.g., Titanium (IV) isopropoxide (M.Wt= $288.25 \mathrm{~g} \mathrm{~mol}^{-1}$, purity $\geq 97.0 \%$ ), ammoniumcerium nitrate $\left(\mathrm{M} . \mathrm{Wt}=548.26 \mathrm{~g} \mathrm{~mol}^{-1}\right.$, purity $\geq 98.0 \%$ ), sodium hydroxide solid $\left(\mathrm{M} . \mathrm{Wt}=39.99 \mathrm{~g} \mathrm{~mol}^{-1}\right.$, purity $\left.\geq 98.0 \%\right)$, sodium hypochlorite (M.Wt $=74.44 \mathrm{~g} \mathrm{~mol}^{-1}$, purity $\geq 98.0 \%$ ), ammonium persulfate $\left(\mathrm{M} . \mathrm{Wt}=228.18 \mathrm{~g} \mathrm{~mol}^{-1}\right.$, purity $\geq 98.0 \%$ ), glutaraldehyde (M.Wt $=100.11 \mathrm{~g} \mathrm{~mol}^{-1}$, purity $\geq 99.0 \%$ ), Ethanol (purity $\geq 99.0 \%$ ), acetic acid (purity $\geq 98.0 \%$ ), Methylene blue dye ( $\mathrm{MWt}=319.85$, purity $\geq 98.0 \%$ ), and methyl orange ( $\mathrm{MWt}=327.33$, purity $\geq 98.0 \%$ ), as the model dye for photocatalytic degradation.

\subsection{Preparation of Cerium Oxide and Cerium titanate NPs using Sunflower seed husk extract}

\subsubsection{Preparation of sunflower seed husk extract}

The husks of sunflower seeds were washed thoroughly with distilled water forremoving adhering soil. Before the extraction process, the washed shells were dried in the sun to evaporate water for 72 hours; the dried sunflower seed husk was ground and sieved. Then, 
about 50 grams of ground powder was treated with $400 \mathrm{ml}$ ethanol. The mix was retained at $25^{\circ} \mathrm{C}$ for $24 \mathrm{~h}$ with continuous shaking and filtered using refinery paper. Then, wash the sunflower husks with distilled water and dry them in an oven at $80^{\circ} \mathrm{C}$ for 24 hours.

\subsubsection{Preparation of Cerium Oxide and Cerium titanate NPs}

For preparing $\mathrm{CeO}_{2} \mathrm{NPs}, 100 \mathrm{ml}$ of sunflower seed husk extract was heated at $80{ }^{\circ} \mathrm{C}$ for one hour, then $0.01 \mathrm{M}$ of ammonium cerium nitrate aqueous solution was added. Cerium hydroxide was precipitated by adding little drops of ammonium hydroxide $\left(\mathrm{NH}_{4} \mathrm{OH}\right)$ solution until the $\mathrm{pH}$ was maintained at 8.6 and reduced to a dark orange solution. The precipitate was filtered and annealed at $500^{\circ} \mathrm{C}$ for $3 \mathrm{~h}$. A yellow precipitate was formed and packed carefully for further characterization.

\subsubsection{Preparatin of Cerium titanate NPs}

Typically, $0.01 \mathrm{M}$ of ammonium cerium nitrate and a different molar ratio of Titanium (IV) isopropoxide $(0.1,0.3$, and $0.5 \mathrm{M})$ were dissolved in 100, 200, and $300 \mathrm{ml}$ of sunflower seed husk extract, respectively. The solution was refluxed for $1 \mathrm{~h}$ with vigorous stirring at 80 ${ }^{\circ} \mathrm{C}$. Cerium titanate was precipitated by adding little drops of ammonium hydroxide $\left(\mathrm{NH}_{4} \mathrm{OH}\right)$ solution until the $\mathrm{pH}$ was maintained at 7.6, 8.6, and 9.5 for $0.1,0.3$, and $0.5 \mathrm{M}$, respectively. The precipitated was filtered, washed with DI water, and annealed at $500^{\circ} \mathrm{C}$ for $3 \mathrm{~h}$. A light-yellow precipitate was obtained and packed carefully for further characterization.

\subsection{Preparation of microcrystalline cellulose fiber from the treated sunflower seeds} husk

The sunflower seed hulls pre-treated with $100 \mathrm{~g}$ ethanol were washed many times with distilled water, and then dried in an oven at $80^{\circ} \mathrm{C}$ for $24 \mathrm{~h}$. The pre-treated waste material was further digested with $18 \%(\mathrm{w} / \mathrm{w}) \mathrm{NaOH}$ alkaline solution at $110^{\circ} \mathrm{C}$ for 1 hour. After digestion, the filtered pulp is thoroughly washed until there is no alkali residue, and the $\mathrm{pH}$ reaches 7 and then dried at $80^{\circ} \mathrm{C}$. The bleaching method was performedby the method characterized by (Alabi et al., 2020) but with a slight modification. In the bleaching procedure, $30 \mathrm{~g}$ of the air-dried samples were placed in a $5 \mathrm{~L}$ Erlenmeyer flask, and $1000 \mathrm{ml}$ of (700 chlorites and $300 \mathrm{ml}$ of $90 \% \mathrm{v} / \mathrm{v}$ acetic acid) were added. The mix was heated in a 70

${ }^{\circ} \mathrm{C}$ water bath for 1 hour with continuous stirring. After processing for 1 hour, drain the sample, add $750 \mathrm{ml}$ of hydrogen peroxide, and heat it in water at $70^{\circ} \mathrm{C}$ for 1 hour with continuous stirring. After treatment, the sample was drained and then extracted with $600 \mathrm{ml}$ of $5 \% \mathrm{w} / \mathrm{v} \mathrm{NaOH}$ at $70^{\circ} \mathrm{C}$ for 1 hour. After the sample was extracted with distilled water, 
the alkali was washed off. This process was carried out three times in sequence and dried in an oven at $80^{\circ} \mathrm{C}$ to obtain pure cellulose fiber $(\mathrm{Cf})$. Finally, the preparation scheme is presented in scheme 1 .

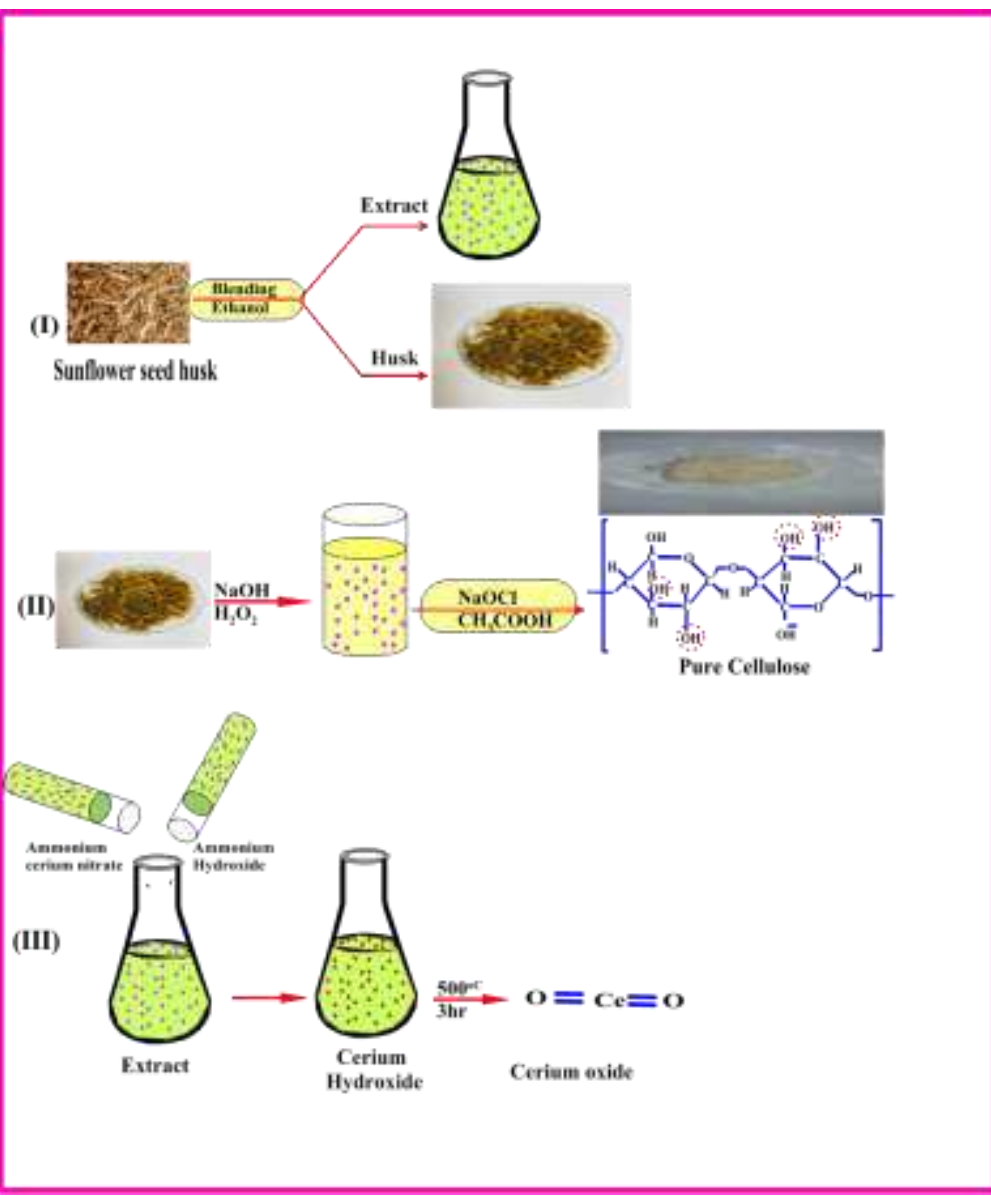

\section{Scheme 1. Schematic diagram for the preparation procedures of $\mathrm{Cf}$ and $\mathrm{CeO}_{2} \mathrm{NPs}_{3}$.}

\subsection{Preparation of cerium titanate cellulose fiber $(\mathrm{Ce}-\mathrm{Ti} / \mathrm{Cf})$ nanocomposite materials}

First, cellulose fibers $(\mathrm{Cf})$ were activated using phosphoric acid as follows: 5 grams of cellulose fiberswere mixed with $200 \mathrm{ml}$ of distilled water, and then $2 \mathrm{ml}$ of $2 \mathrm{M}$ phosphoric acid were added and stirred with vigorous stirring. The mix was retained at $25^{\circ} \mathrm{C}$ for $6 \mathrm{~h}$; $\mathrm{Cf}$ was filtered, washed with DI water, and dried at $50^{\circ} \mathrm{C}$ for $24 \mathrm{~h}$. Second, activated Cf was intercalated using different molar ratios of cerium titanate, as follows: $1 \mathrm{~g}$ of the activated $\mathrm{Cf}$ sample was dispersed in $100 \mathrm{ml}$ of distilled water. Then, $0.08 \mathrm{~g}$ ammonium persulfate was put onto the previous suspension and heated at $80{ }^{\circ} \mathrm{C}$ for $2 \mathrm{~h}$. Then, $0.2 \mathrm{~g}$ of $(0.1,0.3$, and 0.5 M) cerium titanate previously prepared was added and continued for another $2 \mathrm{hr}$ at $80{ }^{\circ} \mathrm{C}$. After mixing the components, the nanocomposite fiber was crosslinked by adding glutaraldehyde solution, and the $\mathrm{pH}$ of the solution was adjusted by using ammonium 
hydroxide solution and become $11.4,11.7$, and 12 for $0.1,0.3$, and $0.5 \mathrm{M}$ cerium titanate, respectively. The crosslinked fiber was heated at $80{ }^{\circ} \mathrm{C}$ for $24 \mathrm{~h}$, washed away with purified water, and dried at $70^{\circ} \mathrm{C}$. The tests were denoted by acronyms describing the composition of the $\mathrm{Cf}$ and the intercalated different molar ratio of cerium titanate; for example, $(0.1 \mathrm{Ce}$ $\mathrm{Ti} / \mathrm{Cf}, 0.3 \mathrm{Ce}-\mathrm{Ti} / \mathrm{Cf}$, and 0.5 Ce-Ti /Cf) represents the Cf intercalated with $0.1 \mathrm{M} \mathrm{Ce}-\mathrm{Ti}, 0.3$ $\mathrm{M} \mathrm{Ce}-\mathrm{Ti}$, and $0.5 \mathrm{M} \mathrm{Ce}-\mathrm{Ti}$, respectively.

\subsection{Characterization}

The chemical functional groups exist in $\mathrm{Cf}, \mathrm{CeO}_{2} \mathrm{NPs}, \mathrm{CeO}_{2} / \mathrm{Cf}$ and different concentration of Ce-Ti loaded cellulose fiber (0.1 Ce-Ti/Cf, 0.3 Ce-Ti /Cf and 0.5 Ce-Ti /Cf) nanocomposite photocatalyst were analyzed with Fourier-transform infrared spectroscopy (FTIR). An FTIR spectrometer (Nicolet Avatar 230 spectrometer) was used to record infrared spectra with wavenumbers between $400 \mathrm{~cm}^{-1}$ and $4000 \mathrm{~cm}^{-1}$ at a rate of 30 scans per minute. Use the wide-angle X-ray diffraction spectrum of $\mathrm{Cu} K$ Ka radiation $(\lambda=0.1542$ nm) (PAN Analytical X'pert Superior Score Plus diffractometer) (model: PW3040 / 60) to obtain the crystal size of $\mathrm{Ce}-\mathrm{Ti}$ cross linked $\mathrm{Cf}$ and exponential influence cellulose fiber crystallinity. The spectrum range is $10^{\circ}$ to $70^{\circ}$ in a step size of $0.05^{\circ}$ (20) at $40 \mathrm{kV}$ and 30 $\mathrm{mA}$. Scherrer's formula aidsin measuring the cellulose crystals'size in the fiber structure (Elenga et al. 2009), and the crystallinity index (CRI) was calculated from the height of the peak (Segal et al. 1959). Energy-dispersive X-ray spectroscopic analysis (EDX) spectroscopy was measured on SEM instrument (an SEM Model Quanta field emission gun (FEG) with applying electrical power $30 \mathrm{kV}$ ) (JEOL Company, Tokyo, Japan) equipped with an Oxford EDAX system. The elemental composition $(\mathrm{C}, \mathrm{H}, \mathrm{N}$, and $\mathrm{S})$ of $\mathrm{Cf}, \mathrm{CeO}_{2}$ NPs, $\mathrm{CeO}_{2} / \mathrm{Cf}, 0.1 \mathrm{Ce}-\mathrm{Ti} / \mathrm{Cf}, 0.3 \mathrm{Ce}-\mathrm{Ti} / \mathrm{Cf}$, and $0.5 \mathrm{Ce}$-Ti /Cf were analyzedby a Thermo Scientific Flash EA 1112. Samples were dried before measurements, and $2.5 \mathrm{mg}$ of each sample was weighted in tin capsules, and the measurements were performed in duplicate.

\subsection{Sunlight photocatalytic activity test}

Photocatalytic tests were performed in a batch experiment. All photocatalytic tests were conducted under the same conditions on sunny days between 8:30 AM and 3:00 PM (the reaction time was $6 \mathrm{~h}$ ), March- April. The ambient temperature was between $26^{\circ} \mathrm{C}$ and $31^{\circ} \mathrm{C}$, and the dye solutions were preparedby using deionized water. A certain mass of the material with the same quantity of $0.1 \mathrm{Ce}-\mathrm{Ti} / \mathrm{Cf}, 0.3 \mathrm{Ce}-\mathrm{Ti} / \mathrm{Cf}$, and $0.5 \mathrm{Ce}-\mathrm{Ti} / \mathrm{Cf}(150 \mathrm{mg})$ was placed into MO or MB aqueous solution in a quartz tube and stirred for $60 \mathrm{~min}$ in the dark to reach the adsorption-desorption equilibrium. Then, the quartz tube was positioned under sunlight. Batch experiments were performed by varying many experimental variables like 
adsorbent dosage ( 0.01 to $0.2 \mathrm{~g}$ ), $\mathrm{pH}$ (2.5 to 10 ), photo degradation time (0 to $300 \mathrm{~min}$ ), and $\mathrm{H}_{2} \mathrm{O}_{2}$ addition to determining the better photocatalytic degradation states. The $\mathrm{pH}$ of $\mathrm{MO}$ and $\mathrm{MB}$ dyes was setbyinserting either $0.10 \mathrm{~mol} / \mathrm{L} \mathrm{NaOH}$ or $\mathrm{HCl}$. After additionof $0.1 \mathrm{Ce}-\mathrm{Ti} / \mathrm{Cf}$, $0.3 \mathrm{Ce}-\mathrm{Ti} / \mathrm{Cf}$, and 0.5 Ce-Ti /Cf nanocomposites, the solution's concentration of MO and MB was monitored by an ultraviolet spectrophotometer (Elico EI 301E, India) at $465 \mathrm{~nm}$, and $664 \mathrm{~nm}$, respectively. The \% degradation of methyl orange or methylene blue dyes at time $t$ was estimatedthrough Eq. (1).

\section{Degradation rate $=\mathrm{C}_{0}-\mathrm{C}_{\mathrm{t}} / \mathrm{C}_{0} \times 100$,}

Where $\mathrm{C}_{0}$ is the initial dye concentration $\left(\mathrm{mg} . \mathrm{L}^{-1}\right)$ and $\mathrm{C}_{\mathrm{t}}$ is the dye concentration $\left(\mathrm{mg} . \mathrm{L}^{-1}\right)$ after time $\mathrm{t}(\mathrm{min})$.

\subsection{Wastewater treatment processes by photocatalytic degradation}

The photocatalytic degradation test was carried out on the actual factory wastewater with a $\mathrm{pH}$ of $7.8 \mathrm{using}$ batch technology under sunlight. Therefore, $1.50 \mathrm{~g}$ of each $0.1 \mathrm{Ce}-\mathrm{Ti} /$ Cf, $0.3 \mathrm{Ce}-\mathrm{Ti} / \mathrm{Cf}$, and 0.5 Ce-Ti / CF nanocomposites were added to $100 \mathrm{ml}$ of actual wastewater and exposed to sunlight at ambient temperature $31{ }^{\circ} \mathrm{C}$ for two hours under magnetic agitation. EC and $\mathrm{pH}$ values wereassessed as described previously (Kotp 2021).Turbidity measurement techniques used as for measuring sulfate $\left(\mathrm{SO}_{4}{ }^{2-}\right)$ ions. Heavy metal ions were considered by ICPS (ICAP 6500 Duo, Thermo Scientific, England). The concentration of $\mathrm{MO}, \mathrm{MB}$, Congo-red, Malachite green, and safranin in the solution was determined by using an ultraviolet spectrophotometer (Elico EI 301E, India) at $465 \mathrm{~nm}, 664$ $\mathrm{nm}, 497 \mathrm{~nm}, 624$, and $473 \mathrm{~nm}$, respectively. The mineralization efficiencies of samples by highly active samples at time t, may be presented as (Capanema et al. 2018):

Mineralization efficiency $=100 *\left(\mathrm{COD}_{0}-\mathrm{COD}_{\mathrm{t}} / \mathrm{COD}_{0}\right)(2)$ where $\mathrm{COD}_{0}$ and $\mathrm{COD}_{\mathrm{t}}$ are the initial and at time tCOD values of the samples solutions.

\subsection{Statistical analysis}

Analysis of variance (ANOVA) was utilized to assess the major essential effects and the interaction effects of parameters affecting the efficiency of the photodegradation process. For statistical significance, this work aimed to obtain the absolute rate of t-ratio to be> 2 or the Pvalue to be $<$ the significance level $(\alpha=0.05)$. P-value was utilized to confirm the significance of every coefficient; if $\mathrm{p}$-value $<0.05$, the model term will be significant.

\section{Results and discussion}

3.1. Characterization of $\mathrm{Cf}, \mathrm{CeO}_{2} \mathrm{NPs}, \mathrm{CeO}_{2} / \mathrm{Cf}$, and different molar ratios of Ce-Ti loaded cellulose fiber (0.1 Ce-Ti/Cf, $0.3 \mathrm{Ce}-\mathrm{Ti} / \mathrm{Cf}$, and $0.5 \mathrm{Ce}$-Ti /Cf) nanocomposite materials 
FTIR analysis was conductedto assess the functional groups responsible for capping, reduction, and nanocomposite formation. Fig.1 (a) shows the FTIR spectra of sunflower seed husk extracts, $\mathrm{Cf}, \mathrm{CeO}_{2} \mathrm{NPs}$, and $\mathrm{CeO}_{2} / \mathrm{Cf}$ nanocomposite in the range of $400-4000 \mathrm{~cm}^{-1}$. As presentedin the figure, the FTIR spectrum of the sunflower husk extract shows a clear peak at the wavelength of $3333 \mathrm{~cm}^{-1}$. The peak at $1610 \mathrm{~cm}^{-1}$ was related to the bond $\mathrm{C}=\mathrm{O}$ stretching vibration of biomolecules involved in filtering (Fahma et al. 2010), while the peak at 3333 $\mathrm{cm}^{-1}$ wasrelated to the $\mathrm{O}-\mathrm{H}$ stretching vibration of phenolic compounds. The band at 2922.5 $\mathrm{cm}^{-1}$ owed to the stretching vibration of the $\mathrm{CH}$ of all hydrocarbon components in polysaccharides (Fahma et al. 2010). The FTIR spectra of $\mathrm{CeO}_{2} \mathrm{NPs}$, Cf, and their composite material $\left(\mathrm{CeO}_{2} / \mathrm{Cf}\right)$ show different peaks; the cerium oxide nanoparticles are shownin Fig. 1 (a). The spectrum clearly shows three strong peaks at $3242,1558 \mathrm{~cm}^{-1}$ and $700 \mathrm{~cm}^{-1}$.

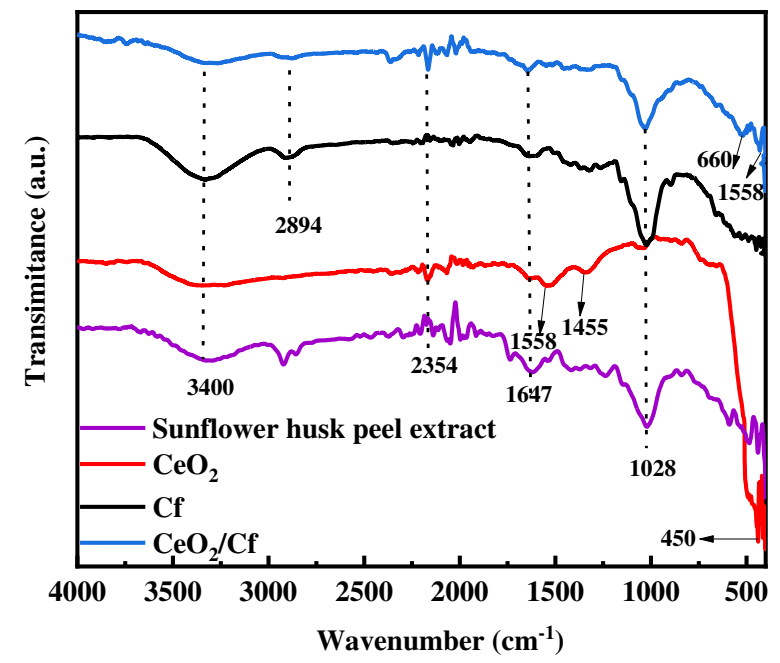

(a)

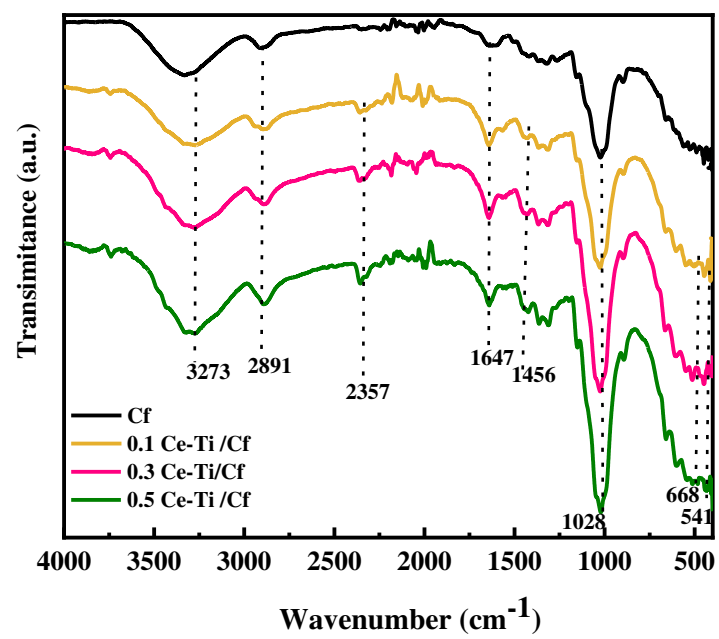


Figure 1. FTIR pattern for Sunflower seed husk extract, $\mathrm{CeO}_{2} \mathrm{NPs}, \mathrm{Cf}$ and $\mathrm{Cf} / \mathrm{CeO}_{2}(\mathrm{a})$ and (0.1 Ce-Ti/Cf, $0.3 \mathrm{Ce}$-Ti/Cf and $0.5 \mathrm{Ce}$-Ti/Cf) nanocomposite materials(b).

Thelargebroadbandat $3242.6 \mathrm{~cm}^{-1}$ isbecause

ofthepresenceofphenoliccompoundsinethanol extract (chlorogenic acid,catechol, ellagic acid, caffeic acid, gallic acid, protocatechin, coumarin, cinnamic acid,and ferulicacid)(Abdeldaiem and Hoda 2014). Theweakabsorptionpeaksat2354and $1430.7 \mathrm{~cm}^{-1}$ werebecauseof thebendingvibrationoftheCHbondsofthemethylandmethylenegroups, respectively(Reddy et al. 2014). Theabsorptionbandcloseto $1634 \mathrm{~cm}^{-1}$ wasbecause of the absorbed water molecule's bending vibration, which can be observed in all samples(Farahmandjou et al.2016) .Thebandat $1455 \mathrm{~cm}^{-1}$ matchestotheC-

Hdeformationofthemethylene,methyl,andmethoxygroupsoflignin(Maheswari et al. 2012). Thepeakat $450-550 \mathrm{~cm}^{-1}$ isbecause oftheO-Ce-O stretchvibrationmode(McDevitt and Baun 1964).

However, in the case of Cf spectra (Fig. 1), the strength of the hemicellulose and lignin bands was reduced because of the destruction of the ester bonds of the carboxyl groups of the lignin and/or hemicellulose by chemical treatment. FTIR analysis confirmed the chemical composition of the sunflower seed extract and also showed that the hemicellulose and lignin contents were significantly removed during the chemical treatment of the $\mathrm{Cf}$ extraction. The peaks observed in the wavenumber range of $3400-2920 \mathrm{~cm}^{-1}$ were characteristic of the stretching vibrations of the $\mathrm{O}-\mathrm{H}$ and $\mathrm{C}-\mathrm{H}$ groups of methyl and methylene in polysaccharides. The broad peak at $3400 \mathrm{~cm}^{-1}$ was characteristic of the hydroxyl stretching vibration in polysaccharides. Thispeakalsoincludesintermolecularandintramolecularhydrogenbondvibrationsincellulose. Thebandat $2894.8 \mathrm{~cm}^{-1}$ wasbecause oftheCHstretchingvibrationofallhydrocarboncomponentsinpolysaccharides(Reddy et al. 2018). Thetypicalbandofcelluloseisobservedintheregionof $1650-900 \mathrm{~cm}^{-1}$, andthepeakat $1647 \mathrm{~cm}^{-1}$ correspondstothevibrationofwatermoleculesabsorbedbycellulose (Hosp odarova et al. 2018). Thesmallabsorptionbandappearsat $1456.8 \mathrm{~cm}^{-1}$, whichcorrespondstotheCHstrainintheligninmethoxyl group. The absorption bands at 1362, $1362,1028 \mathrm{~cm}^{-1}$, and $895.4 \mathrm{~cm}^{-1}$ were associated with the C-O-C pyranose ring skeletal vibrations, C-O stretching, and C-H rocking vibrations from the cellulose, the band at 895.4 $\mathrm{cm}^{-1}$, wasbecause of the amorphous area in cellulose (Poletto et al. 2014).After crosslinking the reaction of $\mathrm{Cf}$ with $\mathrm{CeO}_{2} \mathrm{NPs}\left(\mathrm{CeO}_{2} / \mathrm{Cf}\right)$ at $80{ }^{\circ} \mathrm{C}$ for $24 \mathrm{~h}$ ( Fig. 1a), it was observed 
that the $\left(\mathrm{CeO}_{2} / \mathrm{Cf}\right)$ nanocomposites show characteristic bands of $\mathrm{CeO}_{2} \mathrm{NPs}$ and $\mathrm{Cf}$. However, with a reduction in the band's intensity related to the hydroxyl group at 3400-3200 $\mathrm{cm}^{-1}$ compared to pure $\mathrm{Cf}$ curve, that was measured by the absorbance ratio at $3286 \mathrm{~cm}^{-1}$, associated with the hydrogen bonding stretching vibration $(\mathrm{OH} \ldots \mathrm{OH})$, and the reference band of $\beta 1-4$ glycoside bond at $895.4 \mathrm{~cm}^{-1}$. The shift from 528 to $509 \mathrm{~cm}^{-1}$ of the characteristic peak of $\mathrm{CeO}_{2} \mathrm{NPs}$ indicates interaction between $\mathrm{Cf}$ and cerium oxide in the sample $\left(\mathrm{CeO}_{2} / \mathrm{Cf}\right)$ (Ali et al. 2020). TheseoutcomesindicateastronginteractionbetweenCfandceriumoxideNPsthroughthehydroxyla ndcarboxylgroupsofthefiber.

TheFTIRspectraofnanocompositescrosslinkedwithceriumtitanateandcellulosefibers (0.1Ce-Ti / Cf, 0.3Ce-Ti / Cf,and0.5Ce-Ti / Cf) indifferentmolarratiosarepresentedin(Fig.1b). Compared with the spectra of pristine cellulose fibers, broadband presented at $3273 \mathrm{~cm}^{-1}$ because of the stretching mode of the $\mathrm{O}-\mathrm{H}$ group, which illustrates water content in all samples (Ntwaeaborwa and Holloway 2005). TheexistenceofceriumionsinCe-Ti /Cfwasclarifiedbytheappearanceofpeaksat $541 \mathrm{~cm}^{-1}$ inallthematerialsofCe-Ti

/Cfnanocomposites, andthispeakoccurred because ofCe-O-Ce(Ge et al. 2007). ThebendingvibrationofTi-O bondhasawideabsorptionpeakat $668 \mathrm{~cm}^{-1}$, andlightabsorption at $510 \mathrm{~cm}^{-1}$ was because ofthevibrationofTi-O-Ti vibrationstretching(Kong et al. 2018). ThestrengthofthesetwoabsorptionpeakswasstrengthenedwithanincreaseinmolarratiosCe-Ti, andtheadsorptionofwatermoleculesonthesurfaceofthe samplesCe-Ti / $\mathrm{Cf}$ were improved. ThesefindingsshowastronginteractionbetweenCfandCe-TiNPs through hydroxyl andcarboxylfibergroups.

The XRD patterns of the pure $\mathrm{Cf}, \mathrm{CeO}_{2} \mathrm{NPs}, \mathrm{CeO}_{2} / \mathrm{Cf}$, and different concentrations of Ce-Ti-loaded cellulose fiber (0.1 Ce-Ti/Cf, 0.3 Ce-Ti /Cf, and 0.5 Ce-Ti /Cf)are presented in (Fig. 2). XRD analysis was used to characterize the fibers' crystalline characteristics and determine the relationship between properties and fiber structures.The XRD spectrum (Fig. 2) of $\mathrm{CeO}_{2}$ NPs showed the typical diffraction peaks at $2 \theta=28.38^{\circ}, 32.9^{\circ}, 47.31^{\circ}, 56.26^{\circ}$, and $59.2^{\circ}$, which corresponded to (111), (200),(220), (311), and (222) atomic planes of $\mathrm{CeO}_{2}$ with cubic fluorite lattice structure, respectively, (JCPDS card no.34-0394) (French and Cintron 2013;Adarakatti et al. 2018). The XRD pattern of Cf indicates that the $\mathrm{Cf}$ is semicrystalline in character and showed diffraction peaks at $2 \theta=11.9^{\circ}$ (broad), $19.6^{\circ}$ (sharp), $21,6^{\circ}$ (sharp intense), and $34.8^{\circ}$ (small) related to the (1-10 and 110), (020), and (004) crystallographic planes of the cellulose II, respectively (Reddy et al. 2018;Langan et al. 2021 ).After crosslinking reaction of $\mathrm{Cf}$ with $\mathrm{CeO}_{2} \mathrm{NPs}\left(\mathrm{CeO}_{2} / \mathrm{Cf}\right)$ at $80^{\circ} \mathrm{C}$ for $24 \mathrm{~h}$ (Fig. 2), 
compared to the XRD curve for the control $\mathrm{Cf}$, new peaks were detected in the curve of $\mathrm{Cf}$, this isbecause of the diffraction peaks of the (111), (200), (220), (311), and (222) planes of $\mathrm{CeO}_{2}$ with the cubic fluorite structure (card no. 43-0394). It can also be found that the peaks of $\mathrm{Cf}$ (110) and (020) overlap each other and maybe because of the formation of the nanostructures, lattice strain, and distortion (Agarwal et al. 2018). Furthermore, no peaks from impuritieswere observed in this figure; this clearly illustrates the high purity of all samples prepared. In addition to the diffraction peaks of cellulose fibers and $\mathrm{CeO}_{2} \mathrm{NPs}$, $\mathrm{TiO}_{2}$ anatase was detected in the curves of Ce-Ti loaded with cellulose fibers $(0.1 \mathrm{Ce}-\mathrm{Ti} / \mathrm{Cf}$, $0.3 \mathrm{Ce}-\mathrm{Ti} / \mathrm{Cf}$, and $0.5 \mathrm{Ce}-\mathrm{Ti} / \mathrm{Cf}$ ) in different molar ratios,Fig. (2). However, $\mathrm{TiO}_{2}$ anatase diffraction peaks at $0.1 \mathrm{Ce}-\mathrm{Ti} / \mathrm{Cf}$ and $0.3 \mathrm{Ce}-\mathrm{Ti} / \mathrm{Cf}$ were detected in small amounts on photocatalytic cellulose, and this is because of the low $\mathrm{TiO}_{2}$ content depends on total carbon and cellulose fibers. The strong diffraction peaks at $2 \theta=25.19^{\circ}$ and $48.01^{\circ}$ are also related to the (101) and (200) diffraction planes, respectively,indicating that the $\mathrm{TiO}_{2}$ in the anatase phase is according to card number 21-1272(Chen and Mao 2007).

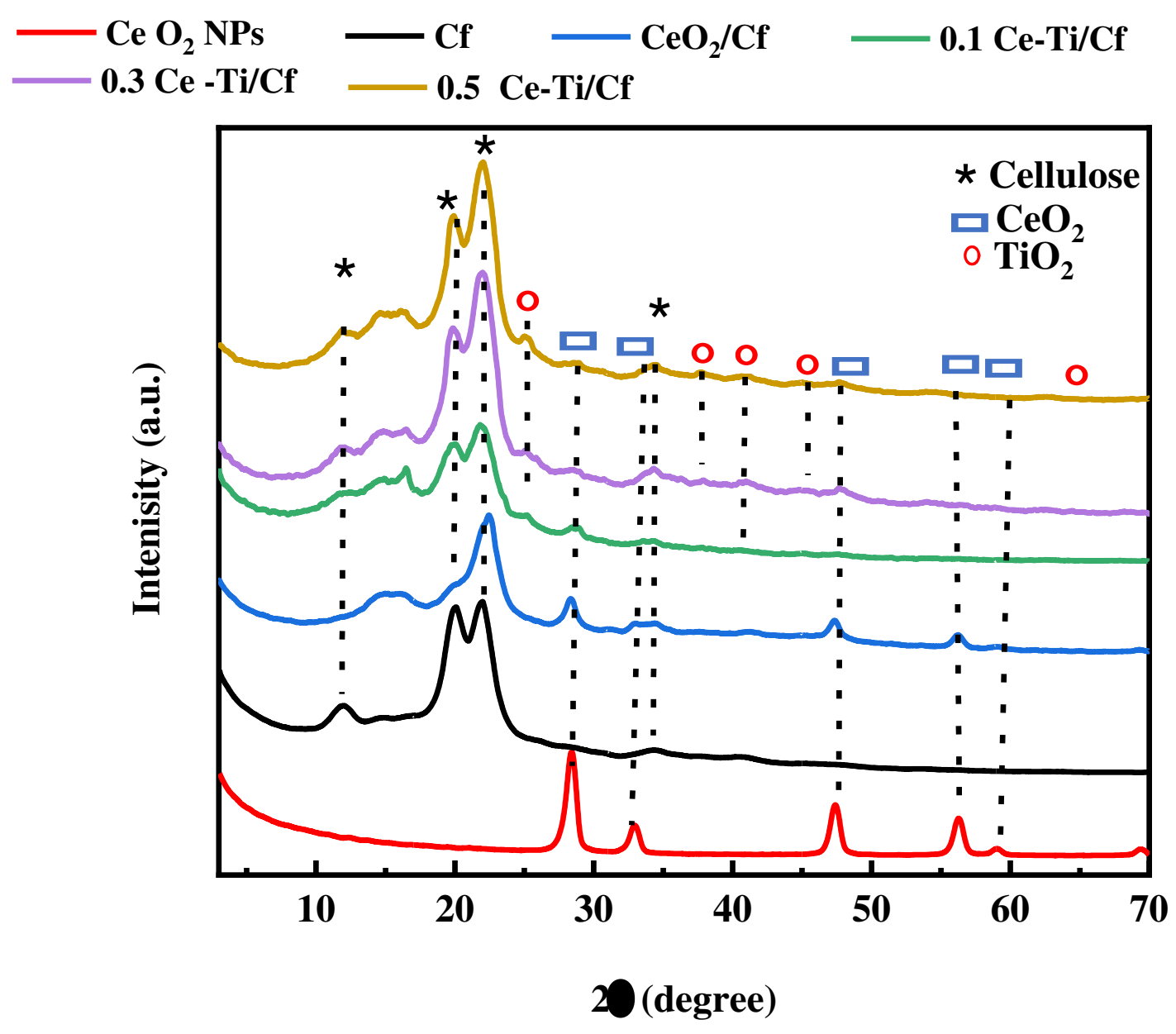


402

403

404

405

406

407

408

409

410

411

412

Figure 2. X-ray diffraction pattern of $\mathrm{CeO}_{2} \mathrm{NPs}$, $\mathrm{Cf}, \mathrm{Cf} / \mathrm{CeO}_{2}, \mathrm{O}_{2} \mathrm{Ce}-\mathrm{Ti} / \mathrm{Cf}, 0.3 \mathrm{Ce}-$ Ti/Cf and 0.5 Ce-Ti/Cf nanocomposite materials.

It is believed that in addition to the peaks at $0.1 \mathrm{Ce}-\mathrm{Ti} / \mathrm{Cf}$, and $0.3 \mathrm{Ce}-\mathrm{Ti} / \mathrm{Cf}$, new peaks appeared at $0.5 \mathrm{Ce}-\mathrm{Ti} / \mathrm{Cf}$ because of the high concentration of $\mathrm{TiO}_{2}$. Crosslinked $\mathrm{TiO}_{2}$ particles are utilized as effectivepositions to generate photogenerated electrons with sunlight, and then $\mathrm{Cf}$ provides trapping sites for photogenerated electrons liberated from titanium oxide conduction band. This should increase the composite fiber's photocatalytic activity and expedite the breakdown of methylene blue and methyl orange (Zhang et al. 2013).The Segal formula calculates the crystallinity index (CI) of different cellulose samples and lists them in Table 1 . The major crystalline peaks occur around $2 \theta=22^{\circ}$ and between $2 \theta$ values of $19^{\circ}$ and $20^{\circ}$, respectively. The Segal crystallinity index ranged from $66.67 \%$ for Cf to $50.00 \%$ for 0.1 Ce-Ti/Cf. Whereas, for Ce-Ti-loaded cellulose fiber $(0.1 \mathrm{Ce}-\mathrm{Ti} / \mathrm{Cf}, 0.3 \mathrm{Ce}-\mathrm{Ti} / \mathrm{Cf}$, and $0.5 \mathrm{Ce}-$ $\mathrm{Ti} / \mathrm{Cf}$ ), the crystallinity index was $50.00 \%, 66.67$, and $66.67 \%$, respectively.

Table 1. Relative crystallinity index (CrI) and d-spacing of $\mathrm{Cf}, \mathrm{Cf} / \mathrm{CeO}_{2}, 0.1 \mathrm{Ce}-\mathrm{Ti} / \mathrm{Cf}$, 0.3 Ce-Ti/Cf and $0.5 \mathrm{Ce}-\mathrm{Ti} / \mathrm{Cf}$ nanocomposite materials.

\begin{tabular}{|c|c|c|c|c|c|}
\hline \multirow[t]{2}{*}{ Material } & \multicolumn{4}{|c|}{ d-spacing (nm) } & \multirow[t]{2}{*}{ CrI \% } \\
\hline & $(1-10)$ & (110) & $(020)$ & $(004)$ & \\
\hline $\mathbf{C f}$ & 7.43 & 4.51 & 4.10 & 2.60 & 66.67 \\
\hline $\mathrm{CeO}_{2} / \mathrm{Cf}$ & 6.16 & 4.43 & 3.93 & 2.58 & 65.75 \\
\hline 0.1 Ce-Ti/Cf & 7.13 & 4.41 & 4.03 & 2.65 & 50.00 \\
\hline $0.3 \mathrm{Ce}-\mathrm{Ti} / \mathrm{Cf}$ & 7.46 & 4.44 & 4.05 & 2.61 & 66.67 \\
\hline $0.5 \mathrm{Ce}-\mathrm{Ti} / \mathrm{Cf}$ & 7.49 & 4.51 & 4.03 & 2.60 & 66.67 \\
\hline
\end{tabular}

These results indicate that incorporating $\mathrm{NPs}$ in $\mathrm{CeO}_{2}$ into $\mathrm{Cf}$ led to the rearrangement of cellulose fiber crystal planes, which may be because of higher hydrophilicity, and thus affinity to interact and contact with $\mathrm{CeO}_{2}$ NPs during the nanocomposite synthesis process. Shao et al. and Gutierrez et al. [Zhang et al. 2013; Gutierrez et al. 2013)reported that the incorporation of Ag NP and titanium/vanadium oxide, respectively, resulted in a significant reduction in the crystallinity index of bacterial cellulose (BC). However, according to this study's findings, (Erokh et al. 2016), observed that $\mathrm{Cu}_{2}$ Onanoparticles synthesized on the surface of cotton fiber do not affect its morphology and structural characteristics. These different impacts of many MNPs on the crystallinity of cellulose-based materials support our claim on the NPs affinity and support materials. Another observation in the XRD spectrum of 
the nanocomposite was the change of some diffraction peaks associated withCfs;for example,

414 the double diffraction peaks at $2 \theta$ of $19.6^{\circ}$ and $21.6^{\circ}$ were changed to a single diffraction 415 peak. This change indicates that after interacting with the $\mathrm{CeO}_{2} \mathrm{NPs}$, the crystalline structure 416 of $\mathrm{Cf}$ in some planes is affected, further confirming the production of real nanocomposites 417 with strong interactions(Erokh et al. 2016). Table 1present a comparison of d-spacing and 418 crystallinity index (CrI) before and after crosslinking reaction. Considering the d- spacing 419 values for the cellulose polymorphs, $\mathrm{CeO}_{2} / \mathrm{Cf}$ presented the smaller d-spacing if compared 420 with Cf.

A scanning electron microscope (SEM) technique was utilized to determine the 422 morphologies of pure cellulose fiber $(\mathrm{Cf}), \mathrm{CeO}_{2} \mathrm{NPs},\left(\mathrm{CeO}_{2} / \mathrm{Cf}\right)$, and different molar ratios of 423 Ce-Ti-loaded cellulose fiber (0.1 Ce-Ti/Cf, 0.3 Ce-Ti /Cf, and 0.5 Ce-Ti /Cf) as presented in 424 Fig. 3.The detailed morphologies of $\mathrm{CeO}_{2} \mathrm{NPs}$ with higher magnifications showed coleuses 425 nanoparticles with asymmetrical shapes and a little number of spherical grains. The average 426 particle size was ranged from 26 to $61 \mathrm{~nm}$ Fig. 3(a); also, (EDXS) spectra proved the 427 existence of $\mathrm{Ce}$ and $\mathrm{O}$ elements in the $\mathrm{CeO}_{2} \mathrm{NPs}$. It can be seen that the pure $\mathrm{Cf}$ presented in 428 Fig.3appears to have a rough and clean surface with streaks because of the elimination of a 429 great amount of hemicellulose closely related to cellulose and other substances by chemical 430 treatment. Higher magnification shows that the surface of the original cellulose fibers is 431 smooth,non-uniform with natural grooves and veins with cylindrical rod-like structures(Zhao 432 et al. 2007).

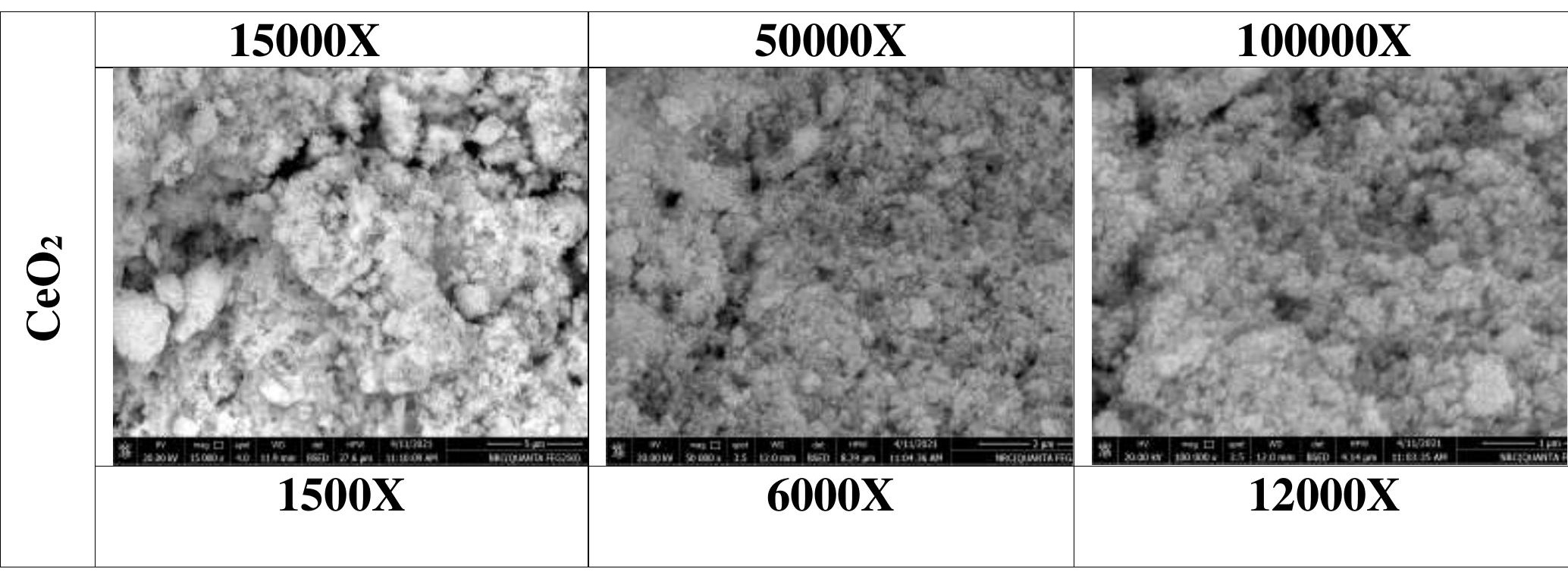




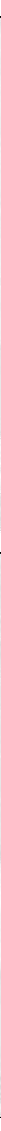

433

(A)

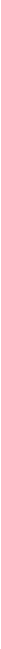




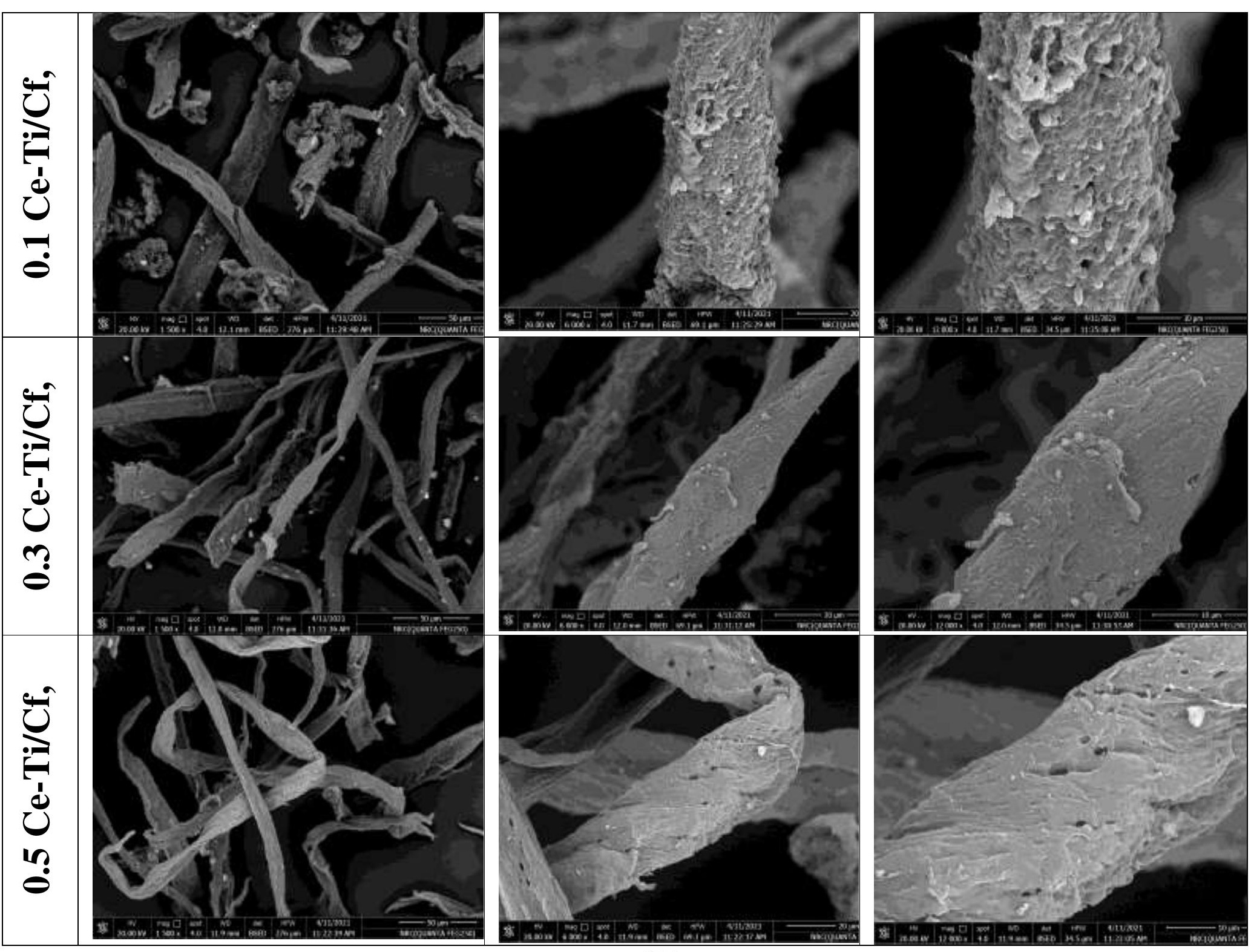

(B)

436 Figure 3. Scanning electron microscopy images of $\mathrm{CeO}_{2} \mathrm{NPs}$, $\mathrm{Cf}$ and $\mathrm{Cf} / \mathrm{CeO}_{2}(\mathrm{~A})$

437 and0.1 Ce-Ti/Cf , $0.3 \mathrm{Ce}-\mathrm{Ti} / \mathrm{Cf}$ and $0.5 \mathrm{Ce}$-Ti/Cf nanocomposite materials(B).

438

The EDX analysis confirmed that $\mathrm{C}$ and $\mathrm{O}$ were the merely elements existed in the cellulose fiber, confirmingthe cellulose fiber host configuration. After crosslinking reaction

440 of $\mathrm{Cf}$ with $\mathrm{CeO}_{2} \mathrm{NPs}\left(\mathrm{CeO}_{2} / \mathrm{Cf}\right)$ at $80^{\circ} \mathrm{C}$ for $24 \mathrm{~h}$, the micrographs were obtained using high

441 magnification, explore the morphology and cross-linkage of $\mathrm{CeO}_{2}$ with $\mathrm{Cf}$. The micrographs

442 show a coarse surface and porous structure because of the crosslinking attachment between

$443 \mathrm{CeO}_{2} \mathrm{NPs}$ and the $\mathrm{Cf}$ polymer matrix, and there are visible points of aggregation. EDXS

444 spectra established the existence of $\mathrm{C}$, $\mathrm{Ce}$, and $\mathrm{O}$ elements in the $\mathrm{CeO}_{2} \mathrm{Cf}$ fiber. When the

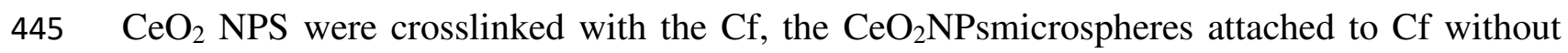


446 destroying the inherent structure of the Cf. The same result was obtained when the 447 incorporation of $\mathrm{TiO}_{2}$ loaded on carbon fibers( Zhang et al. 2013; Wang et al. 2020).

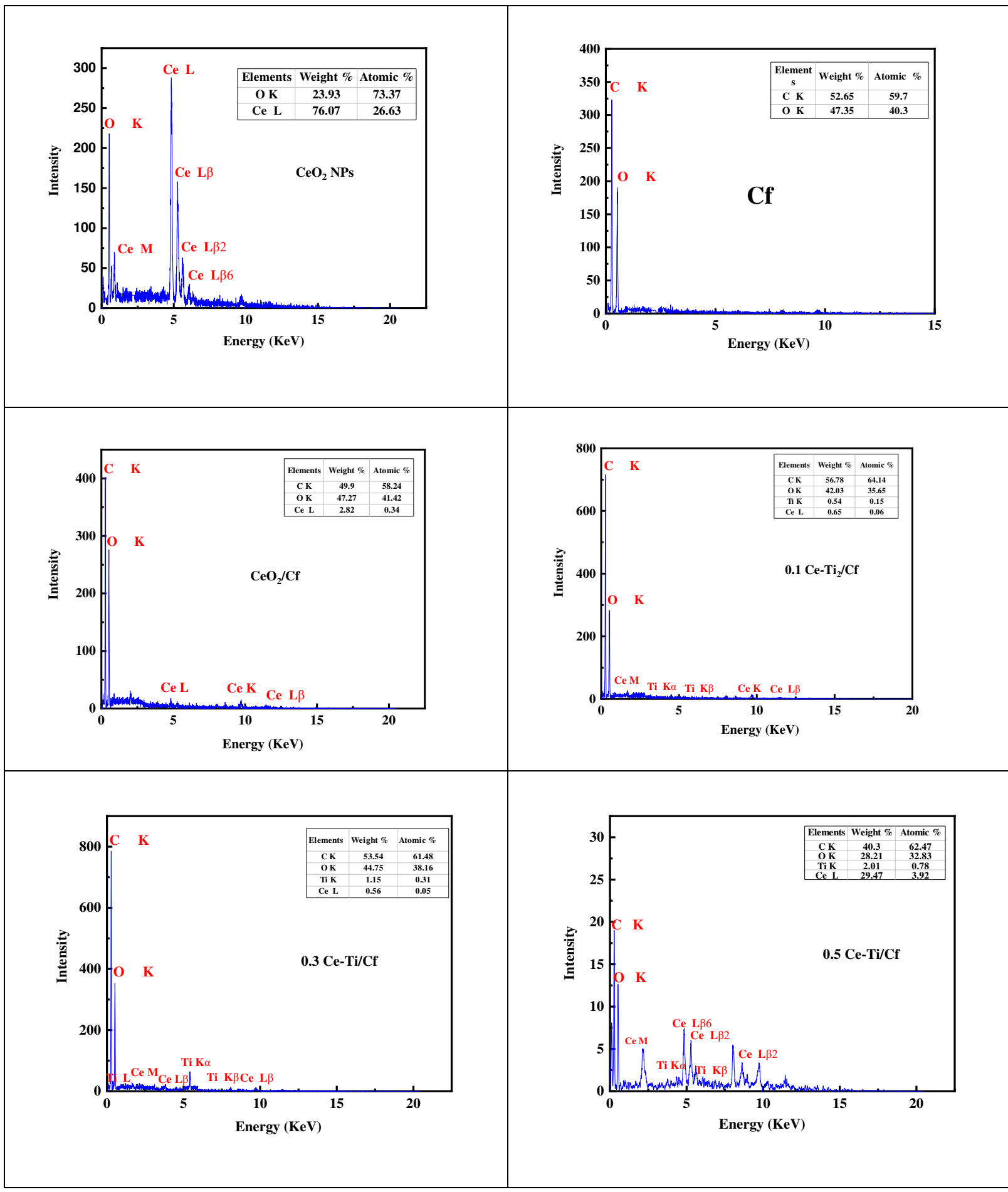

Figure 4. EDX analysis ofCeO2 $\mathrm{NPs}_{2} \mathrm{Cf}, \mathrm{Cf} / \mathrm{CeO}_{2}, \mathrm{O} .1 \mathrm{Ce}-\mathrm{Ti} / \mathrm{Cf}, 0.3 \mathrm{Ce}-\mathrm{Ti} / \mathrm{Cf}$ and 0.5 Ce-Ti/Cf nanocomposite materials. nanocomposite photocatalystillustrates a complex network configuration for these 
photocatalysts, and these fibers containeda lot ofarbitrarily intersecting microfibers with highportionfractions. In addition, NPs from Ce-Ti are attached to the surface of Cf fibers as agglomerates and were unevenly distributed (fiber piecesproducedthrough the crosslinkingmethod) to make anextremely porous structure. Some of these nodes merge the arrangement. The entanglement connecting Ce-Ti NPs and $\mathrm{Cf}$ produces the mechanical features of nanocomposite fibers. EDXS analysis found that $\mathrm{Ce}-\mathrm{Ti} / \mathrm{Cf}$ fiber primarilyconsisted of $\mathrm{O}, \mathrm{Ti}, \mathrm{C}$, and a small amount of $\mathrm{Ce}$, titanium. In addition, heterogeneous accumulation of $\mathrm{Ce}-\mathrm{Ti}$ was also observed in the area between adjacent fiberswhen the amount is increased to $0.5 \mathrm{CeTi}_{2} \mathrm{O}_{6}$. The elemental analysis of pure $\mathrm{Cf}, \mathrm{CeO}_{2}$ $\mathrm{NPs}, \mathrm{CeO}_{2} / \mathrm{Cf}$, and Ce-Ti-crosslinked cellulose fibers $(0.1 \mathrm{Ce}-\mathrm{Ti} / \mathrm{Cf}, 0.3 \mathrm{Ce}-\mathrm{Ti} / \mathrm{Cf}$, and 0.5 $\mathrm{Ce}-\mathrm{Ti} / \mathrm{Cf}$ ) are presented in (Table 2). The elemental atomic composition of cellulose fiber (Cf) was $39.3 \% \mathrm{C}, 5.6 \% \mathrm{H}$, and $0 \% \mathrm{~N}$. The $\mathrm{N}$ and $\mathrm{C}$ contents of cellulose fibers as the same as the $\mathrm{N}$, and $\mathrm{C}$ content of commercial cellulose (Biswal 2004), the elemental survey analysis of $\mathrm{CeO}_{2} \mathrm{NPs}$ was $0.36 \% \mathrm{C}, 0.12 \% \mathrm{H}$. The observed contents of $\mathrm{C}$ and $\mathrm{H}$ for green synthesized $\mathrm{CeO}_{2}$ NPs werepossibly observedbecause of the presence of few traces of plant extract or adsorption of organic impurities through synthesis (Sharma et al. 2017). When the $\mathrm{CeO}_{2}$ NPS were crosslinked with $\mathrm{Cf}$, the $\mathrm{C}$ and $\mathrm{N}$ contents in $\left(\mathrm{CeO}_{2} / \mathrm{Cf}\right)$ were $38.7 \% \mathrm{C}, 5.27$ $\% \mathrm{H}$, and $1.25 \% \mathrm{~N}$. The nitrogen content nanocomposite material $(0.1 \mathrm{Ce}-\mathrm{Ti} / \mathrm{Cf}, 0.3 \mathrm{Ce}-$ $\mathrm{Ti} / \mathrm{Cf}$, and $0.5 \mathrm{Ce}-\mathrm{Ti} / \mathrm{Cf}$ ) was found to be $0.88,1.5$, and 2.4 , respectively, which increases as the Ce-Ti molar ratio increases, as presented in (Table 2), in addition to carbon content decreased to $42.3,41.5$, and 40.1, respectively. The considerable percentage of nitrogen in the crosslinked reaction was accounted for the presence of crosslinked $\mathrm{Ce}$-Ti chains; the variation in the nitrogen content, although not much, is significant in the case of $0.5 \mathrm{Ce}-\mathrm{Ti} / \mathrm{Cf}$. This is because of the higher Ce-Ti content in the nanocomposite polymer, which is also because of the higher number of moles of $\mathrm{Ce}-\mathrm{Ti}$ in the reaction feed. Among other crosslinked polymers, $0.1 \mathrm{Ce}-\mathrm{Ti} / \mathrm{Cf}$ has the lowest nitrogen content, when compared with other nanocomposites in this series (Gurung et al. 2014).

Table2. Elemental Analysis of the pure cellulose fiber $(\mathrm{Cf}), \mathrm{CeO}_{2} \mathrm{NPs}, \mathrm{Cf} / \mathrm{CeO}_{2}, \mathrm{0.1} \mathrm{Ce}-$

$\mathrm{Ti} / \mathrm{Cf}, 0.3 \mathrm{Ce}-\mathrm{Ti} / \mathrm{Cf}$ and $0.5 \mathrm{Ce}$-Ti /Cf nanocomposite materials.

\begin{tabular}{ccccc}
\hline \multirow{2}{*}{ Materials } & \multicolumn{4}{c}{ Elemental composition \% } \\
\cline { 2 - 5 } & $\mathrm{N}$ & $\mathrm{C}$ & $\mathrm{H}$ & $\mathrm{S}$ \\
\hline $\mathrm{Cf}$ & 0 & 39.3 & 5.6 & 0 \\
$\mathrm{CeO}_{2} \mathrm{NPs}$ & 0 & 0.36 & 0.12 & 0 \\
$\mathrm{CeO}_{2} / \mathrm{Cf}$ & 1.25 & 38.7 & 5.27 & 0
\end{tabular}




\subsection{Dye removal investigations}

As illustrated in characterization tests, the synthesized $\mathrm{Cf}, \mathrm{CeO}_{2} \mathrm{NPs}, \mathrm{CeO}_{2} / \mathrm{Cf}$, and different concentrations of $\mathrm{Ce}-\mathrm{Ti}$ loaded cellulose fiber $(0.1 \mathrm{Ce}-\mathrm{Ti} / \mathrm{Cf}, 0.3 \mathrm{Ce}-\mathrm{Ti} / \mathrm{Cf}$, and 0.5 $\mathrm{Ce}-\mathrm{Ti} / \mathrm{Cf}$ ) nanocomposite photocatalyst have been successfully fabricated according to FESEM, FTIR, and XRD analyses. The photocatalytic degradation capabilities of the samples under sunlight illuminations were estimatedthrough degradation of methylene blue (MB) and methyl orange (MO), as model organic compounds found in wastewaters:

\subsubsection{Effects of dose on photocatalytic activity}

491 Catalyst dosage affects the efficiency of photodegradation. Different $\mathrm{Cf}, \mathrm{CeO}_{2} \mathrm{NPs}, \mathrm{CeO}_{2} / \mathrm{Cf}$, $4920.1 \mathrm{Ce}-\mathrm{Ti} / \mathrm{Cf}, 0.3 \mathrm{Ce}-\mathrm{Ti} / \mathrm{Cf}$, and $0.5 \mathrm{Ce}-\mathrm{Ti} / \mathrm{Cf}$ nanocomposite materials doses in the range of 493 1-20 $\mathrm{mg} \mathrm{L}^{-1}$ were dispersed into $20 \mathrm{~mL}$ solution of $\mathrm{MO}$ and $\mathrm{MB}$ at a concentration of $100 \mathrm{mg}$ $494 \mathrm{~L}^{-1}$. Before sunlight, adsorption equilibrium was reached by agitation at $120 \mathrm{rpm}$ for 60 495 minutes in the dark. Fig. 5 shows the relationship between the photodegradation rate of 496 nanocomposite materials for raw $\mathrm{Cf}, \mathrm{CeO}_{2} \mathrm{NPs}$, and $\mathrm{CeO}_{2} / \mathrm{Cf}, 0.1 \mathrm{Ce}-\mathrm{Ti} / \mathrm{Cf}, 0.3 \mathrm{Ce}-\mathrm{Ti} / \mathrm{Cf}, 0.5$ $497 \mathrm{Ce}-\mathrm{Ti} / \mathrm{Cf}$ doses. As expected, the photodegradation efficiency increased with the catalyst 498 dose because more binding sites were available for degradation. The reactivity of $0.1 \mathrm{Ce}-$ 499 Ti/Cf, 0.3 Ce-Ti/Cf, and 0.5 Ce-Ti/Cf at $20 \mathrm{mg} \mathrm{L}^{-1}$ was two times higher than raw $\mathrm{Cf}$. 


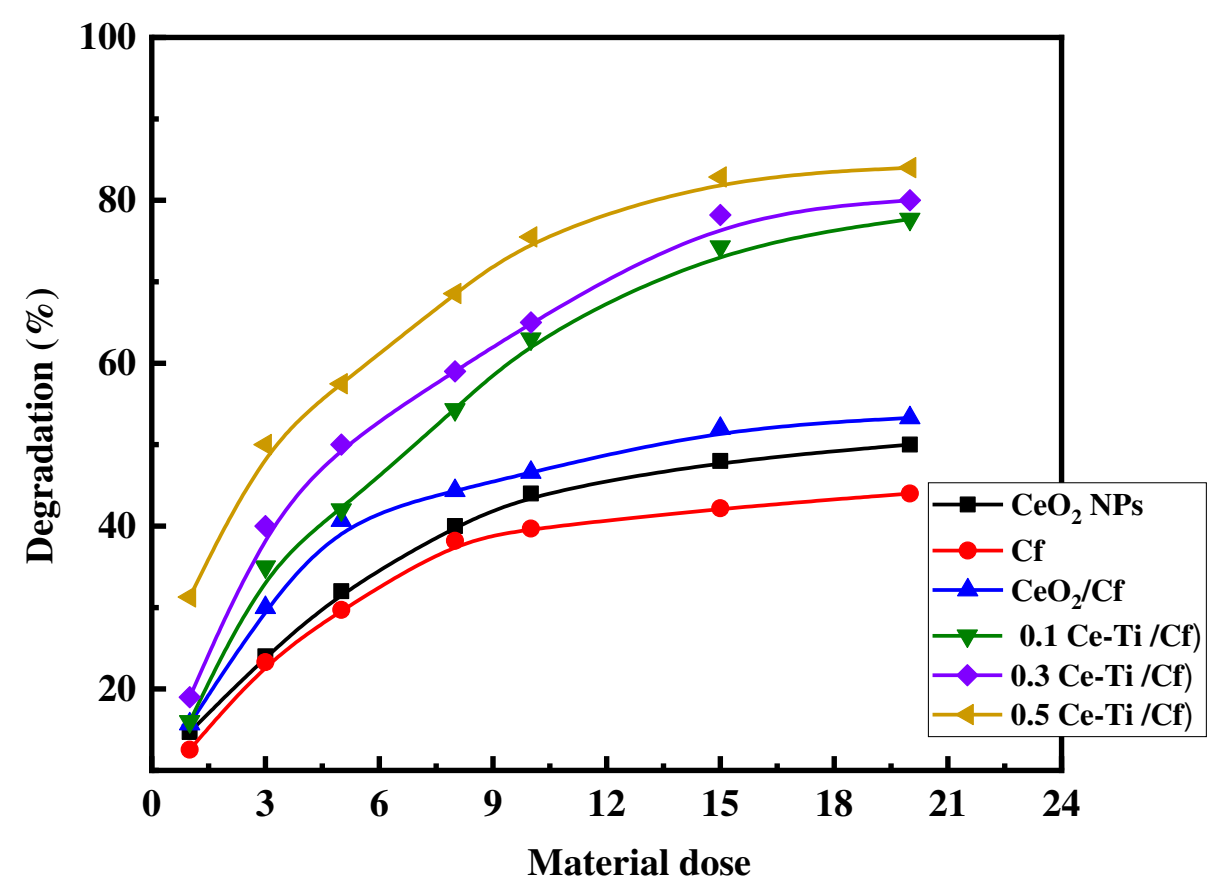

(a)

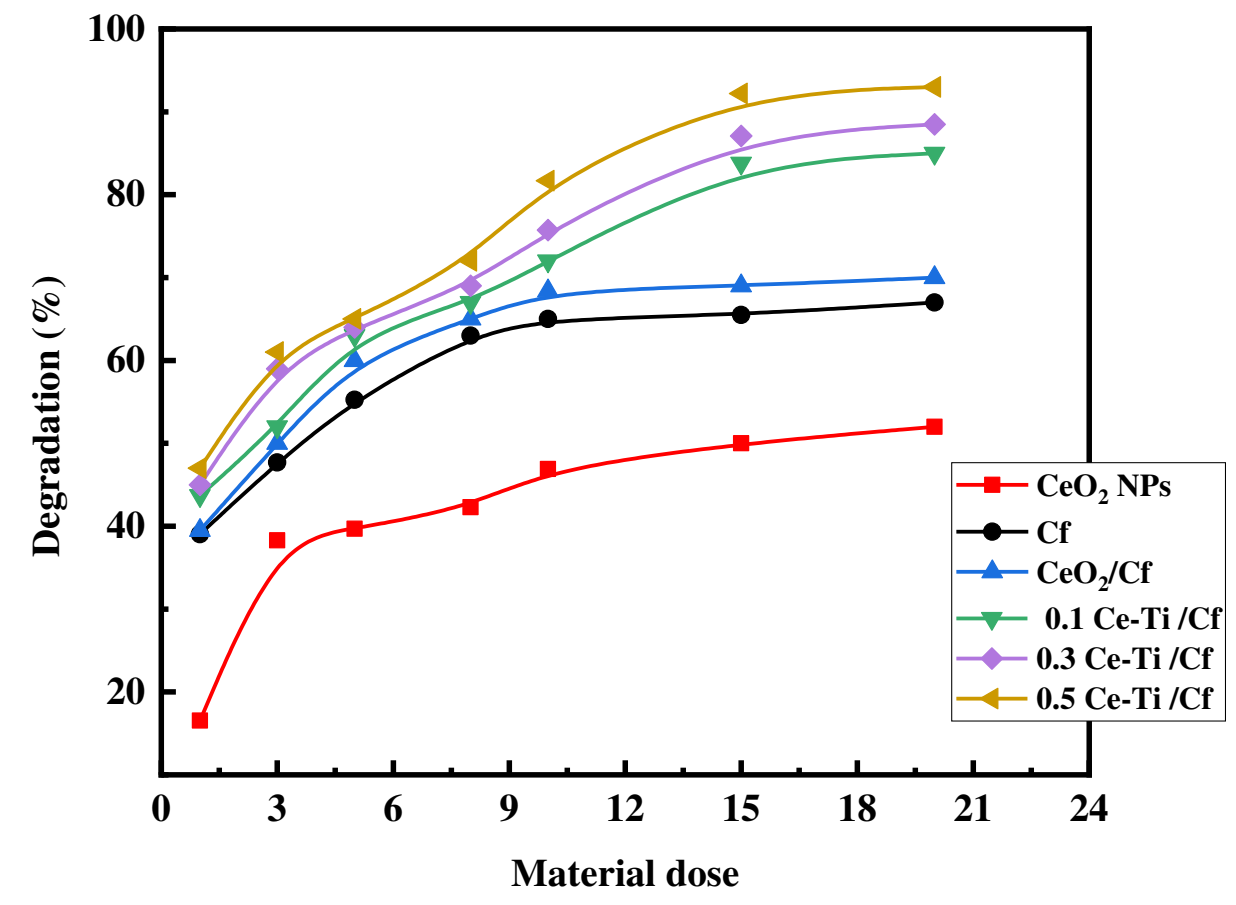

(b)

Figure 5. Photocatalytic efficiency of $\mathrm{MB}(\mathrm{a})$ and $\mathrm{MO}(\mathrm{b})$ with different amount of $\mathrm{CeO}_{2}$ materials. 
504 However, the $15 \mathrm{mg} \mathrm{L}^{-1}$ dose showed the same good degradation behaviour as $20 \mathrm{mg} \mathrm{L}^{-1}$, which is the reason behind its selection as the standard for subsequent experiments. Therefore, the nanocomposites 0.1 Ce-Ti / Cf, $0.3 \mathrm{Ce}-\mathrm{Ti} / \mathrm{Cf}$, and $0.5 \mathrm{Ce}-\mathrm{Ti} / \mathrm{Cf}$ show the highest catalytic capacity to degrade MB and MO. The degradation rate of $0.5 \mathrm{Ce}-\mathrm{Ti} / \mathrm{Cf}$ can degrade MB and MO more than $85 \%$ and $93 \%$ in 5 hours, respectively, indicating that active species that can degrade MB and MO dyes are easily produced during the activation process. However, when Ce-Ti nanoparticles are directly crosslinked with cellulose fibers, the rate of discoloration increases because of the presence of Ce-Ti nanoparticles in the manufacture of nanocomposites(Kotp 2020). Therefore, it can be concluded that Cf has a positive effect on the decolorationprocess. This increased decolorationcan be because of the charge separation caused by the $\mathrm{Ce}-\mathrm{Ti}$ charge on the $\mathrm{Cf}$. For $\mathrm{Cf}$ with $\mathrm{Ce}-\mathrm{Ti}$, the mainpart of $\mathrm{Cf}$ is to transport electrons from Ce-Ti NPs, making it difficult to recombine electron pairs(Kotp 2020. Longerlived electron-hole pairs led to the generation of a large number of photoreactive species.Furthermore, because of the adsorption capacity of $\mathrm{Cf}$ and the porous structure of the nanocomposite, the MO and MB molecules are concentrated around $\mathrm{Ce}-\mathrm{Ti} / \mathrm{Cf}$, that increases the probability that the MO and MB molecules diffuse and migrate to the exteriorbelow a concentration slope. Therefore, the degradation percentage and the adequacy of MO and MB are correspondingly enhanced. As per the "Adsorb \& Shuttle" (A\&S) strategy, pollutants are adsorbed first and then disperse to the $\mathrm{TiO}_{2}$ particles for degradation (Kedem et al. 2009). Additionally, the loss of MO and MB is certainly attributable to photocatalytic degradation rather than adsorption.In all cases, there is still a little amount of $\mathrm{MO}$ and $\mathrm{MB}$ in the solution, thoseearnings that the remaining organic matter or intermediates are difficult to fully degrade because of the blocking of photocatalytic active sites in the process(An et al. 2012). Results show a notable difference in the degradation efficiency by $0.1 \mathrm{Ce}$-Ti/Cf, $0.3 \mathrm{Ce}$-Ti/Cf, 0.5 $\mathrm{Ce}-\mathrm{Ti} / \mathrm{Cf}, \mathrm{Cf}, \mathrm{CeO}_{2} \mathrm{NPs}$, and $\mathrm{CeO}_{2} / \mathrm{Cf}$. Therefore, 0.1 Ce-Ti/Cf, 0.3 Ce-Ti/Cf, and $0.5 \mathrm{Ce}-$ Ti/Cf nanocomposite materials were used as the photocatalyst to investigate the removal of the MBand MO dyes in the following experiments, and the optimum dose is favoured at 15 $\mathrm{mg} / \mathrm{L}$.

\subsubsection{The Effectof $\mathrm{pH}$ of $\mathrm{MO}$ and $\mathrm{MB}$ solutions on photocatalytic degradation}

The $\mathrm{pH}$ value has a majorimpact on the exterior charge performance of the photocatalyst (Luo et al. 2015). In this experiment, sodium hydroxide and hydrochloric acid were utilized to adjust the $\mathrm{pH}$ of dye solutions. MO solution is orange in acidic condition and yellow in alkaline condition. The impact of change of the $\mathrm{pH}$ value from 2 to 10 , and the initial dye 

nanocomposite fibers in $20 \mathrm{ml}$ solution of MB and MO for 5hours were plotted in (Fig. 6).

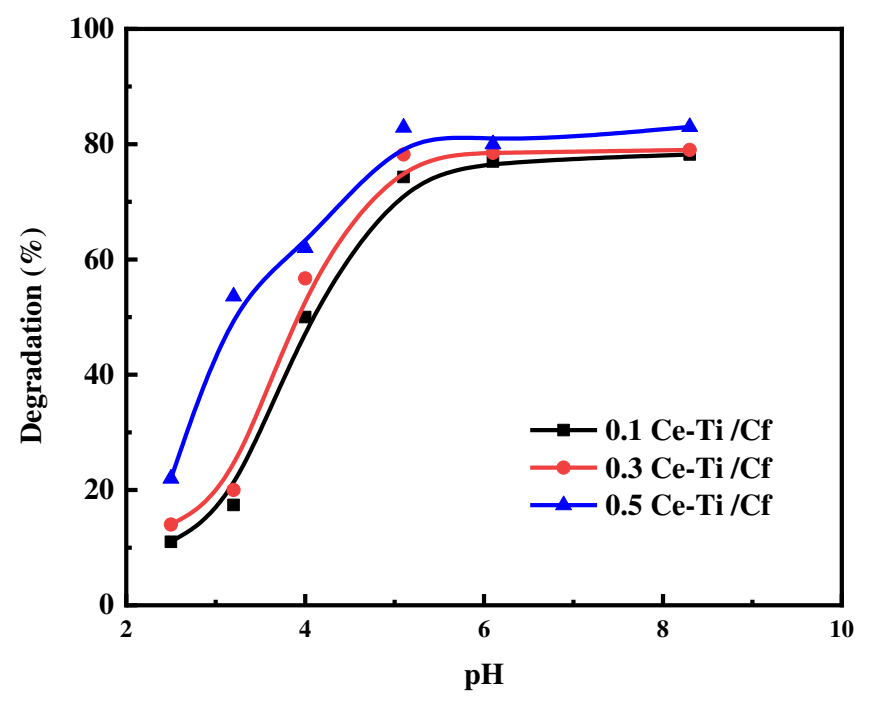

(a)

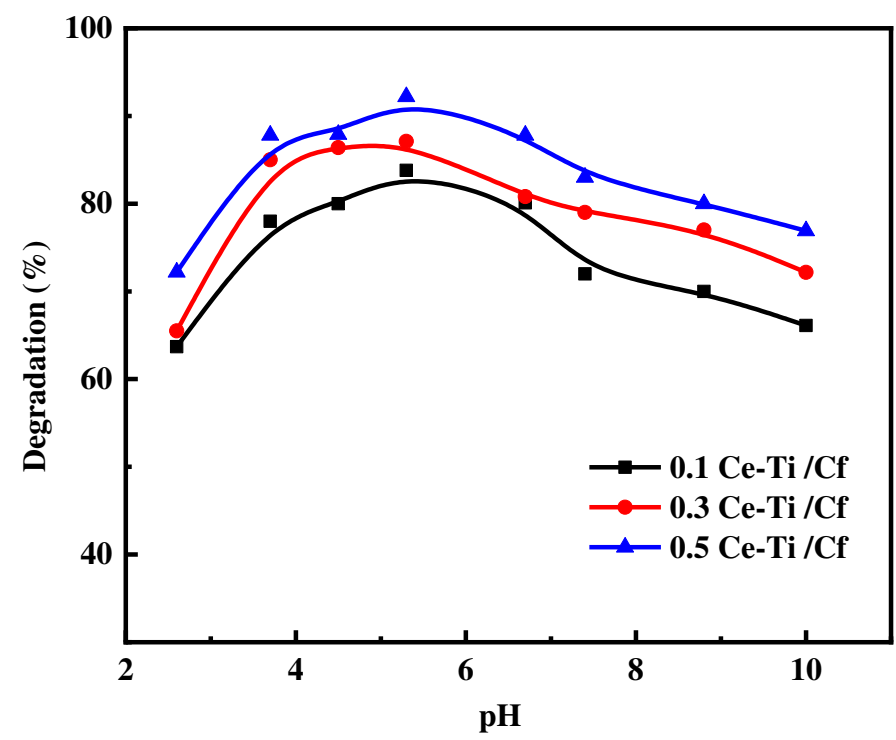

(b)

539

Figure 6. Influence of solution $\mathrm{pH}$ in the photodegradation of $\mathrm{MB}$ (a) and MO (b) $(10 \mathrm{~mL} 100 \mathrm{mg} / \mathrm{L} \mathrm{MB}$ and MO, $0.15 \mathrm{~g}$ of $0.1 \mathrm{Ce}-\mathrm{Ti} / \mathrm{Cf}, 0.3 \mathrm{Ce}-\mathrm{Ti} / \mathrm{Cf}$ and $0.5 \mathrm{Ce}-\mathrm{Ti} / \mathrm{Cf}$, reaction time: 5 h.)

The degradation efficiency of $\mathrm{MB}$ raised with raising the $\mathrm{pH}$ value from acidic to alkaline direction, as shown in (Fig. 6a). The samebehaviour has been stated previously by titaniasilica/cobalt ferrite photocatalyst (Harraz et al. 2014). The pH value mainly affects the surface charge characteristics of the photocatalyst. In an alkaline solution, the surface of $\mathrm{Ce}$ Ti can be negatively charged, while in an acid solution, it is positively charged (Zhang et al. 
2018; Vieira et al. 2018). MB is a cationic dye, and it has a great tendency to be adsorbed onto the $0.1 \mathrm{Ce}-\mathrm{Ti} / \mathrm{Cf}, 0.3 \mathrm{Ce}-\mathrm{Ti} / \mathrm{Cf}$, and $0.5 \mathrm{Ce}-\mathrm{Ti} / \mathrm{Cf}$ surfaces at alkaline $\mathrm{pH}$. This is because of the highest degradation of 78.2, 79, and 83 was achieved at $\mathrm{pH} 8.3$, while a degradation efficiency of only 11,14 , and $22 \%$ was obtained at acidic $\mathrm{pH} 2$ for $0.1 \mathrm{Ce}-\mathrm{Ti} / \mathrm{Cf}, 0.3 \mathrm{Ce}-$ $\mathrm{Ti} / \mathrm{Cf}$, and $0.5 \mathrm{Ce}-\mathrm{Ti} / \mathrm{Cf}$, respectively. This finding demonstrates that photodegradation happens at the catalyst interface, not in bulk solution.

Additionally, it is reasonable to suppose that the interaction between hydroxide ions $\left(\mathrm{OH}^{-}\right)$and photogenerated holes to create hydroxyl radicals $\left(\mathrm{OH}^{-}\right)$is improved at alkaline $\mathrm{pH}$, which would assist photocatalytic degradation of MB (Harraz et al. 2014).As presented in (Figure $6 \mathrm{~b}$ ), the reduction in $\mathrm{pH}$ significantly enhanced the photodegradation of $0.1 \mathrm{Ce}-\mathrm{Ti} /$ Cf, $0.3 \mathrm{Ce}-\mathrm{Ti} / \mathrm{Cf}$, and $0.5 \mathrm{Ce}-\mathrm{Ti} / \mathrm{Cf}$ nanocomposites for MO. The improved adsorption at lower $\mathrm{pH}$ wasbecauseof the increased interaction connecting the protonated electrostatic MO and the negatively charged $\mathrm{Cf}$ or the sulfonic acid type of $\mathrm{MO}$ and the positively charged $\mathrm{Ce}-$ Ti NPs that have been crosslinked with the Cf. As soon as the $\mathrm{pH}$ value is less than 4.00, the negative charge of the $\mathrm{Cf}$ is extensivelydeclinedbecauseof the reduction of the separation of the carboxyl group, which leads to the reduction of the MO photodegradation. According to the work of the Andronic team (Andronic and Duta 2008), it can be seen that pH 5.3 is also conducive to MO photocatalytic reaction because of higher MO adsorption and the formation of azo structure in MO molecules. Then, choose the optimal $\mathrm{pH}$ value of 5.3 for the next experiment(Zhang et al. 2013; Kotp 2017). It can also be found from (Fig. 6) that the degradation efficiency of $\mathrm{MB}$ and $\mathrm{MO}$ increased in the order, $0.1 \mathrm{Ce}-\mathrm{Ti} / \mathrm{Cf}<0.3 \mathrm{Ce}-\mathrm{Ti} / \mathrm{Cf}$ $<0.5 \mathrm{Ce}-\mathrm{Ti} / \mathrm{Cf}$, the $0.5 \mathrm{Ce}-\mathrm{Ti} / \mathrm{Cf}$ nanocomposite materials and showed highly efficient photocatalytic activity under sunlight irradiation, as a result of the nano-scale effect of $\mathrm{TiO}_{2}$ anatase nanoparticles. A further increase in the amount of $\mathrm{TiO}_{2}$ induced an increase in the photocatalytic MB and MO degradation(Wang et al. 2017).

\subsubsection{Effect of degradation time}

The impact of contact time on the degradation of $\mathrm{MB}$ and $\mathrm{MO}$ in the presence and absence of $\mathrm{H}_{2} \mathrm{O}_{2}$ by $0.1 \mathrm{Ce}-\mathrm{Ti} / \mathrm{Cf}, 0.3 \mathrm{Ce}-\mathrm{Ti} / \mathrm{Cf}$, and $0.5 \mathrm{Ce}-\mathrm{Ti} / \mathrm{Cf}$ nanocomposite materials at optimum $\mathrm{pH}$ and adsorbent dosage was examined. The findings of this investigation are summarized in (Figs. 7,8). The results indicate that/ the adsorption capacity and percentage of dye degradation increase significantly during the early contact time, they slow down after 120 minutes and achieve near equilibrium at about 240 minutes. As a result, the equilibrium period between dye and adsorbent is optimized to 240 minutes. A comparison of the degradation efficiency with and without $\mathrm{H}_{2} \mathrm{O}_{2}$ indicates that $\mathrm{H}_{2} \mathrm{O}_{2}$ enhances the degradation 
ability of the nanocomposite sites at the early interval times and reaches almost equilibrium at

583 about $60 \mathrm{~min}$, as presented in (Figs. 7,8).

584
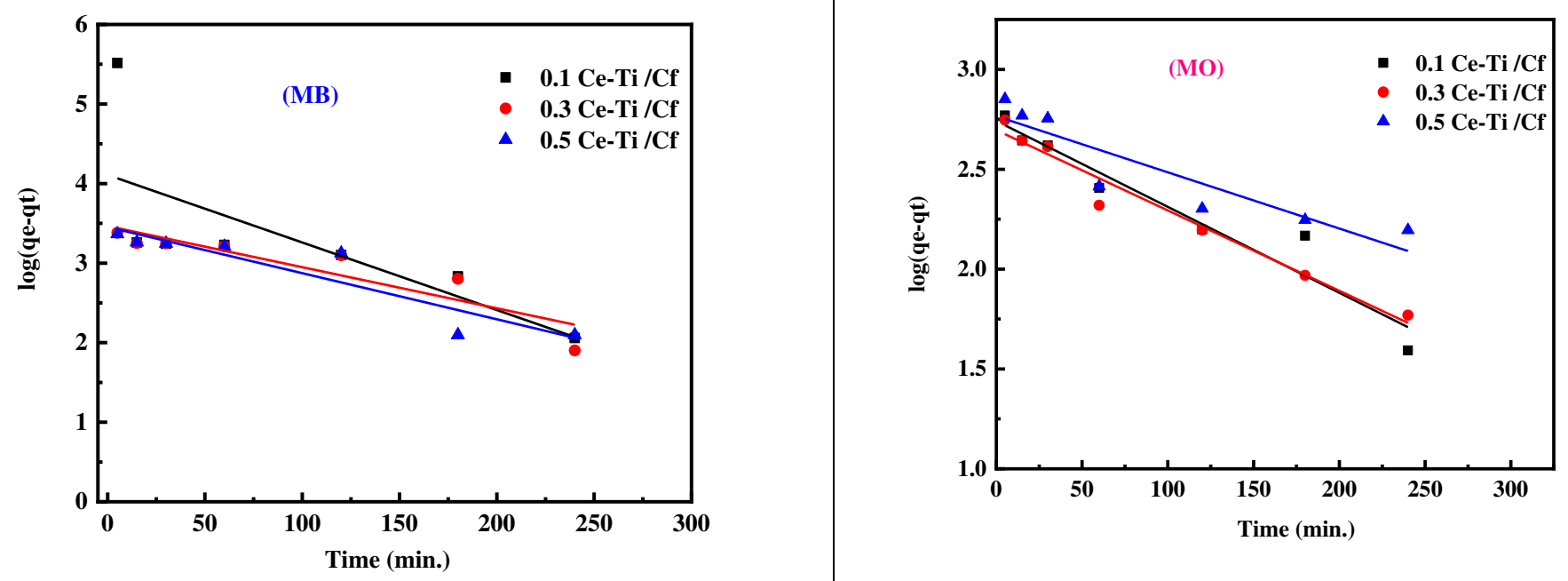

(a)
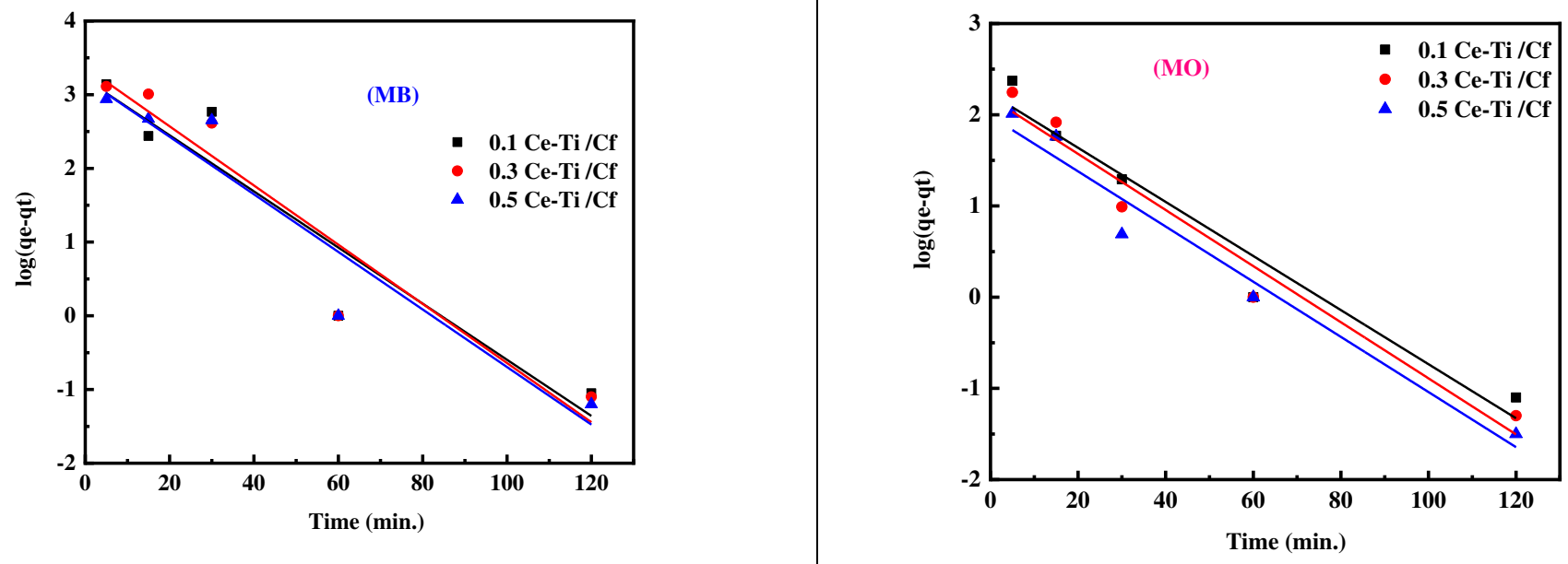

(b)

586 Figure 7. Linear fitting plots of a pseudo-first-order kinetic model for MB and MO

587 photocatalytic degradation onto $(0.1 \mathrm{Ce}-\mathrm{Ti} / \mathrm{Cf}, \mathbf{0 . 3} \mathrm{Ce}-\mathrm{Ti} / \mathrm{Cf}$ and $0.5 \mathrm{Ce}-\mathrm{Ti} / \mathrm{Cf}$

588 nanocomposite materials in the absence (a) and presence of $\mathrm{H}_{2} \mathrm{O}_{2}$. 

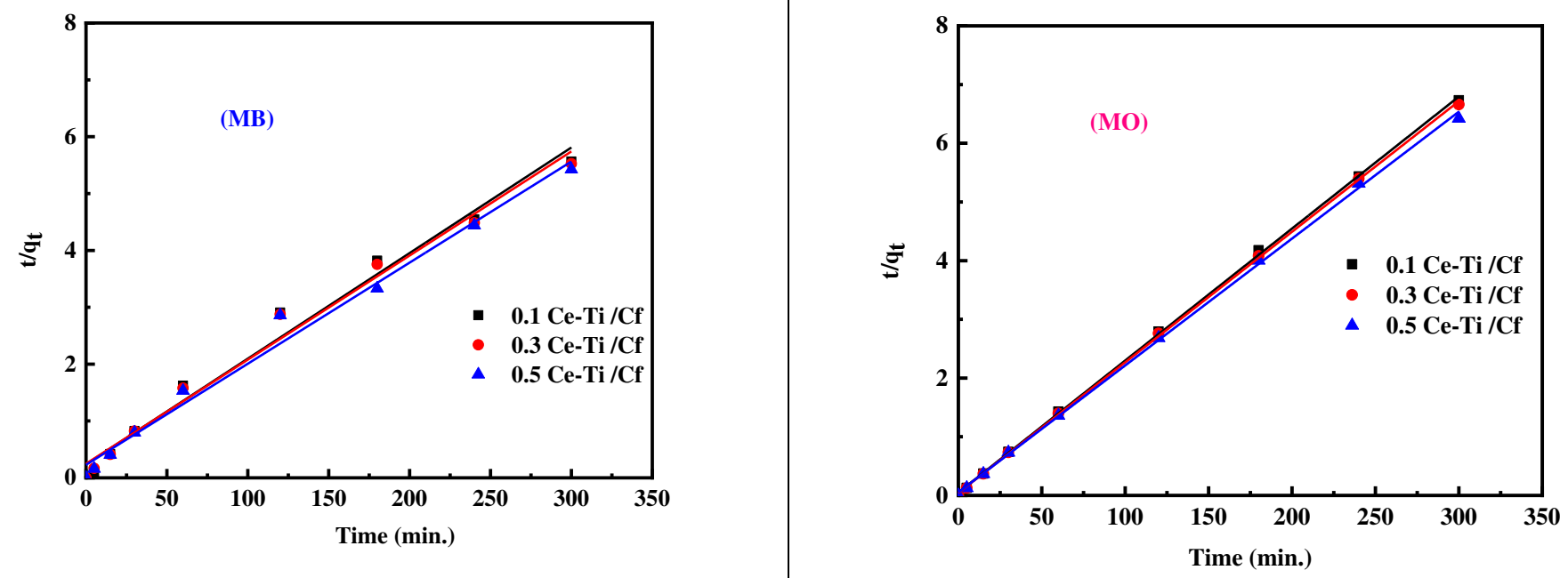

(a)
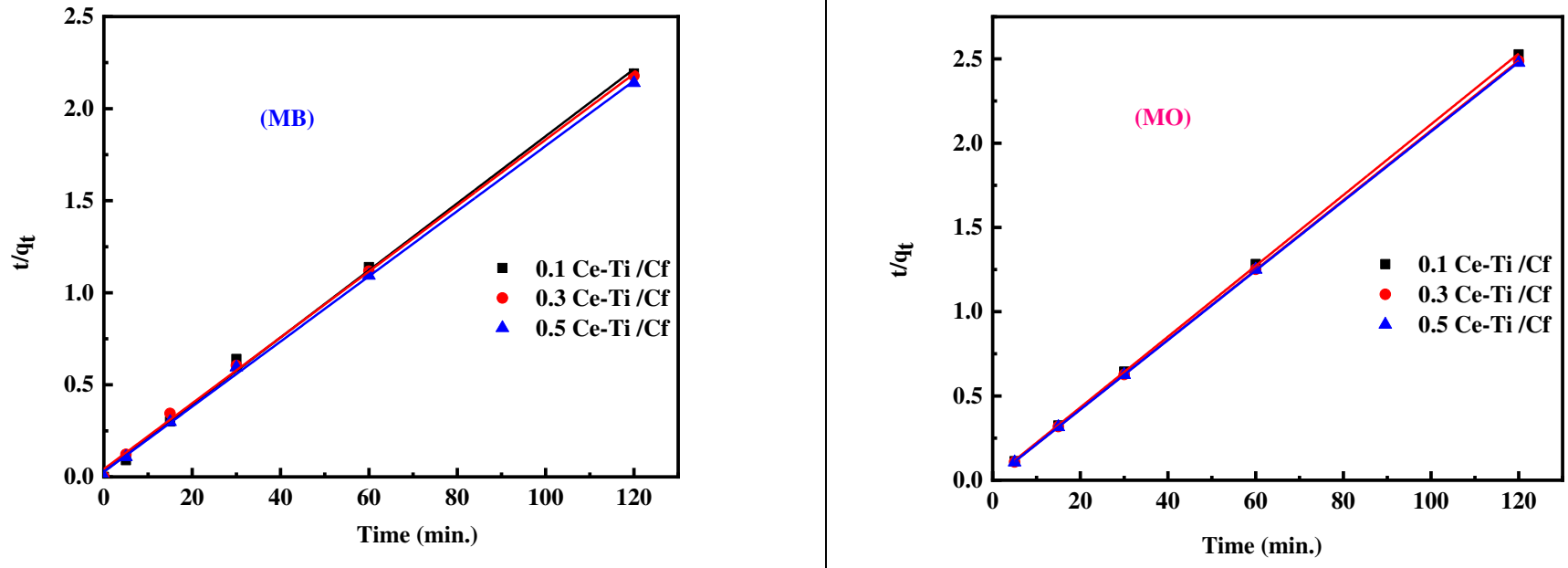

(b)

600 Figure 8. Linear fitting plots of a pseudo-second-order kinetic model for MB and MO 601 photocatalytic degradation onto $(0.1 \mathrm{Ce}-\mathrm{Ti} / \mathrm{Cf}, 0.3 \mathrm{Ce}-\mathrm{Ti} / \mathrm{Cf}$ and $0.5 \mathrm{Ce}-\mathrm{Ti} / \mathrm{Cf})$ nanocomposite materials in the absence (a) and presence of $\mathrm{H}_{2} \mathrm{O}_{2}(\mathrm{~b})$.

The improvement of photodegradation of MB and MO with0.1 Ce-Ti/Cf, $0.3 \mathrm{Ce}$ $\mathrm{Ti} / \mathrm{Cf}$,and $0.5 \mathrm{Ce}-\mathrm{Ti} / \mathrm{Cf}$ nanocomposite materials in the presence of $\mathrm{H}_{2} \mathrm{O}_{2}$ maybe because of the combined impacts of photodissociation of $\mathrm{H}_{2} \mathrm{O}_{2}$ with light and on the photocatalystsurface, and the complex transport of highly reactive hydroxyl radical $\left(\mathrm{OH}^{\bullet}\right)$ in the reactant mix. As 
per the literature (Barakat et al. 2005; Chiou et al. 2008), the next reaction schemes of the photolysis of $\mathrm{H}_{2} \mathrm{O}_{2}$ are possible:

$$
\mathrm{H}_{2} \mathrm{O}_{2}+h v \rightarrow 2 \mathrm{OH}^{\bullet}(3)
$$

$$
2 \mathrm{H}_{2} \mathrm{O}_{2} \rightarrow 2 \mathrm{H}_{2} \mathrm{O}+\mathrm{O}_{2}(4)
$$

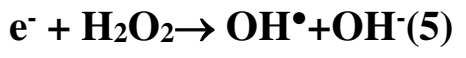

According to the reaction designs, the critical step is forming hydroxyl radicals via photolysis of $\mathrm{H}_{2} \mathrm{O}_{2}$, which can then be employed to react with organic compounds. $\mathrm{H}_{2} \mathrm{O}_{2}$ can potentially serve as an electron scavenger during photocatalysis. The hydroxide ion formed during the electron scavenging process of $\mathrm{H}_{2} \mathrm{O}_{2}$ may combine with holes $\left(\mathrm{h}^{+}\right)$, thus decreasing electronhole recombination in the photocatalyst's molecular orbital (Chen et al. 1998; Yu et al. 2014). The superoxide ion $\left(\mathrm{O}_{2}^{-}\right)$formed during the reaction can be employed to oxidize the organic molecule, but it is not as effective as the hydroxyl radical (Barakat et al. 2005). Along with photolysis, $\mathrm{H}_{2} \mathrm{O}_{2}$ may dissociate on the surface of the photocatalyst, resulting in the next reactions, as per Miller et al. (Miller and Valentine 1999).

$$
\mathrm{C}^{+}+\mathrm{H}_{2} \mathrm{O}_{2} \rightarrow \mathbf{C}+\mathrm{H}^{+}+\mathrm{HO}_{2}{ }^{\bullet}\left(\mathrm{C}^{+}=\text {Oxidized catalyzed surface }\right)(\mathbf{9})
$$

$$
\mathbf{C}+\mathbf{H}_{2} \mathrm{O}_{2} \rightarrow \mathbf{O H}^{-}+\mathbf{O H}^{\bullet}(\mathrm{C}=\text { Reduced catalyzed surface })(\mathbf{1 0})
$$

$$
\mathrm{C}^{+}+\mathrm{O}_{2}^{-} \rightarrow \mathrm{C}+\mathrm{O}_{2}
$$

$$
\begin{aligned}
& \mathrm{C}+\mathrm{OH}^{\bullet}{ }_{2} \rightarrow \mathrm{C}^{+}+\mathrm{HO}_{2}^{-}(12) \\
& \mathrm{C}+\mathrm{OH}^{\bullet} \rightarrow \mathrm{C}^{+}+\mathrm{OH}^{-}(13)
\end{aligned}
$$

Clearly, $\mathrm{H}_{2} \mathrm{O}_{2}$ can react with both reduced and oxidized catalyst surfaces in these model equations, and the catalyst and $\mathrm{H}_{2} \mathrm{O}_{2}$ can conduct concurrent redox reactions. These reactions create extra hydroxyl radicals and ions, serving as electron/hole scavengers and reacting with organic compounds. As demonstrated in the reaction (11-13), hydroxyl, superoxide, and per hydroxyl radials could additionally react on the catalyst surface, thereby cumulatively enhancing the photocatalytic reaction. This set of reactions may explain the increase in the overall photodegradation rate of methylene blue and methyl orange in $0.1 \mathrm{Ce}-\mathrm{Ti} / \mathrm{Cf}, 0.3 \mathrm{Ce}-$ $\mathrm{Ti} / \mathrm{Cf}$, and $0.5 \mathrm{Ce}-\mathrm{Ti} / \mathrm{Cf}$ nanocomposite materials. To explore the degradation reaction kinetics of MB and MO by $0.1 \mathrm{Ce}-\mathrm{Ti} / \mathrm{Cf}, 0.3 \mathrm{Ce}-\mathrm{Ti} / \mathrm{Cf}$, and $0.5 \mathrm{Ce}-\mathrm{Ti} / \mathrm{Cf}$ were used in the present work, pseudo-first-order (Eq.14), and pseudo-second-order (Eq. 15), through the application of linearized equations: 
$642 \log (\mathbf{q e}-\mathbf{q t})=\log q e-\frac{K 1 t}{2.303}(14)$

$643 \quad \frac{t}{q t}=\frac{1}{K 2 \times q e 2}+\frac{t}{q e}(15)$

644

645

where qt and qe $(\mathrm{mg} / \mathrm{g})$ denote the dye's adsorption capacity at time $\mathrm{t}$ and equilibrium, respectively, and $\mathrm{k} 1\left(\mathrm{~min}^{-1}\right)$ and $\mathrm{k} 2(\mathrm{~g} /(\mathrm{mg} \min ))$ denote pseudo-first- and pseudo-secondorder efficiency constants, respectively. The kinetic factors adsorption capacity, rate constant, and correlation coefficient $\left(\mathrm{R}^{2}\right)$ were calculated from linear plots of $\lg$ (qe-qt) versus time for the pseudo-first-order model and t/qt overtime for the pseudo-second-order model, as shown in (Tables 3,4). Following a comparison of the correlation coefficients for pseudo-first- and pseudo-second-order (presented in Fig.8), it is clear that the adsorption behaviour of MB and MO onto $0.1 \mathrm{Ce}-\mathrm{Ti} / \mathrm{Cf}, 0.3 \mathrm{Ce}-\mathrm{Ti} / \mathrm{Cf}$, and $0.5 \mathrm{Ce}-\mathrm{Ti} / \mathrm{Cf}$ nanocomposite materials follow pseudo-second-order kinetics $\left(\mathrm{R}^{2}>0.99\right)$ rather than first-order. The $\mathrm{R}^{2}$ value for the pseudosecond-order model was greater compared to the pseudo-first-order model.

Furthermore, the experimental qe value (qe, exp) was more consistent with the estimated values (qe, cal) derived from pseudo-second-order kinetics. Thus, these considerations show that the degradation of $\mathrm{MB}$ and $\mathrm{MO}$ is a chemical process, owing to the considerable role of chemical bonding and electron transfer. Additionally, the rate-limiting step could be a chemical reaction, and intra-particle diffusion could be involved in the process (Tajizadegan et al. 2015; Zhai et al. 2018).Furthermore, all samples showed excellent photocatalytic activity for the degradation of $\mathrm{MO}$ and $\mathrm{MB}$, reaching approximately 95.4 and 92.7, respectively, for $0.5 \mathrm{Ce}-\mathrm{Ti} / \mathrm{Cf}$ within $300 \mathrm{~min}$ under sunlight. Meanwhile, the photodegradation rates for $0.1 \mathrm{Ce}-\mathrm{Ti} / \mathrm{Cf}(91.12 \%, 90.39 \%)$ and $0.3 \mathrm{Ce}-\mathrm{Ti} / \mathrm{Cf}(92 \%, 91 \%)$ for $\mathrm{MO}$ and MB, respectively. These results can be because of the higher molar ratio of Ce-Ti contents of the $\mathrm{Ce}-\mathrm{Ti} / \mathrm{Cf}$ nanocomposite fibers with stronger degradation properties according to EDXS spectra. Based on the results presented above, sample $0.5 \mathrm{Ce}$-Ti/Cf prepared using $0.5 \mathrm{M} \mathrm{Ce}-\mathrm{Ti}$ NPs and reduction time of $300 \mathrm{~min}$ was chosen to investigate representative material performance further. 
674 Table3. Photodegradation kinetic parameters for the MB and MO degradation 675 without $\mathrm{H}_{2} \mathrm{O}_{2}$ addition.

\begin{tabular}{|c|c|c|c|c|c|c|c|c|c|}
\hline \multirow[b]{3}{*}{ Materials } & \multicolumn{9}{|c|}{ Pseudo-first-order model } \\
\hline & \multicolumn{4}{|c|}{ MB } & \multicolumn{5}{|c|}{ MO } \\
\hline & $\begin{array}{c}\mathrm{q}_{\mathrm{e}, \mathrm{exp}} \\
(\mathrm{mg} / \mathrm{g})\end{array}$ & $\begin{array}{c}\mathbf{K}_{1} \\
\left(\mathbf{m i n}^{-1}\right)\end{array}$ & $\begin{array}{c}\mathrm{q}_{\mathrm{e}, \mathrm{cal}} \\
(\mathrm{mg} / \mathrm{g})\end{array}$ & $\overline{\mathbf{R}^{2}}$ & $\begin{array}{c}\mathrm{q}_{\mathrm{e},}, \exp \\
(\mathrm{mg} / \mathrm{g})\end{array}$ & $\begin{array}{c}\mathbf{K}_{1} \\
\left(\mathbf{m i n}^{-1}\right)\end{array}$ & $\begin{array}{r}\mathbf{q e}, \mathrm{C} \\
(\mathrm{mg}\end{array}$ & & $\overline{\mathbf{R}^{2}}$ \\
\hline $0.1 \mathrm{Ce}-\mathrm{Ti} / \mathrm{Cf}$ & 50.5 & 0.019 & 12.82 & 0.52 & 44.56 & 0.0090 & & .08 & 0.93 \\
\hline 0.3 Ce-Ti/Cf & 53.92 & 0.115 & 28.84 & 0.82 & 45.05 & 0.0092 & & .97 & 0.96 \\
\hline $0.5 \mathrm{Ce}-\mathrm{Ti} / \mathrm{Cf}$ & 54.29 & 0.133 & 28.98 & 0.86 & 46.71 & 0.0064 & & .54 & 0.83 \\
\hline \multicolumn{10}{|c|}{ Pseudo-second-order model } \\
\hline & \multicolumn{4}{|c|}{ MB } & \multicolumn{5}{|c|}{ MO } \\
\hline Materials & $\begin{array}{c}\mathbf{K}_{\mathbf{2}} \\
(\mathrm{g} / \mathrm{mg} \min )\end{array}$ & & $\begin{array}{l}\text { cal } \\
\mathrm{g} / \mathrm{g})\end{array}$ & $\overline{\mathbf{R}^{2}}$ & $\begin{array}{c}\mathbf{K}_{2} \\
(\mathrm{~g} / \mathrm{mg} \min )\end{array}$ & $\begin{array}{l}\mathbf{q e}_{\mathrm{e}}, \\
(\mathbf{m}\end{array}$ & & & $\overline{\mathbf{R}^{2}}$ \\
\hline 0.1 Ce-Ti/Cf & \multicolumn{2}{|c|}{0.002} & 55.55 & 0.98 & \multicolumn{3}{|c|}{45.45} & \multicolumn{2}{|l|}{0.99} \\
\hline $0.3 \mathrm{Ce}-\mathrm{Ti} / \mathrm{Cf}$ & \multicolumn{2}{|c|}{0.003} & 54.64 & 0.98 & \multicolumn{3}{|c|}{45.45} & \multicolumn{2}{|l|}{0.99} \\
\hline $0.5 \mathrm{Ce}-\mathrm{Ti} / \mathrm{Cf}$ & \multicolumn{2}{|c|}{0.003} & 58.82 & 0.98 & \multicolumn{3}{|c|}{49.23} & \multicolumn{2}{|l|}{0.99} \\
\hline
\end{tabular}

677

678

679

680 Table 4. Photodegradation kinetic parameters for the MB and MO degradation in the 681 presence of $\mathrm{H}_{2} \mathrm{O}_{2}$.

\begin{tabular}{|c|c|c|c|c|c|c|c|c|c|}
\hline \multirow[b]{3}{*}{ Materials } & \multicolumn{9}{|c|}{ Pseudo-first-order model } \\
\hline & \multicolumn{4}{|c|}{ MB } & \multicolumn{5}{|c|}{ MO } \\
\hline & $\begin{array}{l}q_{\mathrm{e}}, \exp \\
(\mathrm{mg} / \mathrm{g})\end{array}$ & $\begin{array}{c}\mathbf{K}_{1} \\
\left(\mathbf{m i n}^{-1}\right)\end{array}$ & $\begin{array}{c}\text { qe,cal } \\
(\mathrm{mg} / \mathrm{g})\end{array}$ & $\mathbf{R}^{2}$ & $\begin{array}{l}q_{e}, \exp \\
(\mathrm{mg} / \mathrm{g})\end{array}$ & $\begin{array}{c}\mathbf{K}_{1} \\
\left(\mathbf{m i n}^{-1}\right)\end{array}$ & $\begin{array}{r}\mathbf{q}_{\mathrm{e}, \mathrm{c}} \\
(\mathbf{m g} /\end{array}$ & & $\overline{\mathbf{R}^{2}}$ \\
\hline $0.1 \mathrm{Ce}-\mathrm{Ti} / \mathrm{Cf}$ & 52.67 & 0.087 & 162.18 & 0.96 & 46.76 & 0.066 & 169.8 & 244 & 0.89 \\
\hline $0.3 \mathrm{Ce}-\mathrm{Ti} / \mathrm{Cf}$ & 53.69 & 0.092 & 234.42 & 0.96 & 47.94 & 0.069 & 151.3 & 561 & 0.91 \\
\hline $0.5 \mathrm{Ce}-\mathrm{Ti} / \mathrm{Cf}$ & 54.88 & 0.089 & 158.42 & 0.96 & 48.09 & 0.069 & 95.49 & 926 & 0.91 \\
\hline \multicolumn{10}{|c|}{ Pseudo-second-order model } \\
\hline & \multicolumn{4}{|c|}{ MB } & \multicolumn{5}{|c|}{ MO } \\
\hline Materials & $\begin{array}{c}\mathbf{K}_{\mathbf{2}} \\
(\mathrm{g} / \mathrm{mg} \min )\end{array}$ & & $\begin{array}{l}\text { cal } \\
\text { g/g) }\end{array}$ & $\overline{\mathbf{R}^{2}}$ & $\begin{array}{c}\mathbf{K}_{2} \\
(\mathrm{~g} / \mathrm{mg} \min )\end{array}$ & $\begin{array}{c}\mathbf{q e}, \mathrm{C} \\
(\mathrm{mg}\end{array}$ & & & $\overline{\mathbf{R}^{2}}$ \\
\hline $0.1 \mathrm{Ce}-\mathrm{Ti} / \mathrm{Cf}$ & \multicolumn{2}{|c|}{0.011} & 54.94 & 0.99 & 0.033 & & 50 & 0.99 & \\
\hline $0.3 \mathrm{Ce}-\mathrm{Ti} / \mathrm{Cf}$ & \multicolumn{2}{|c|}{0.007} & 56.17 & 0.99 & 0.054 & & 58.54 & 0.99 & \\
\hline $0.5 \mathrm{Ce}-\mathrm{Ti} / \mathrm{Cf}$ & \multicolumn{2}{|c|}{0.011} & 58.49 & 0.99 & 0.060 & & 59.54 & 0.99 & \\
\hline
\end{tabular}

682

\subsection{Photocatalytic mechanism}

The increased photocatalytic activity of the $0.1 \mathrm{Ce}-\mathrm{Ti} / \mathrm{Cf}, 0.3 \mathrm{Ce}-\mathrm{Ti} / \mathrm{Cf}$, and $0.5 \mathrm{Ce}-$

$686 \mathrm{Ti} / \mathrm{Cf}$ nanocomposite materials can be attributed to the increased charge separation caused by 687 the integration of varying molar ratios of Ce-Ti NPs into the Cf. It is well established that the 
photocatalyst's photogenerated electron-hole separation efficiency is proportional to its quantum efficiency and light energy utilization ratio. As illustrated in Fig.9, when the Ce-

690

691

692

693

694

695

696

697

698

699

700

701

702

703

704

705

706

707

708

709

710

711

712

713

714

715

716

717

718

719

720 Ti/Cf nanocomposite photocatalyst is exposed to sunlight, crosslinked $\mathrm{Cf}$ is easily excited, generating photoinduced holes and electrons. The band structures of crosslinked $\mathrm{Cf}$ and $\mathrm{Ce}-$ Ti were found to be quite similar, with $\mathrm{Cf}$ having a greater conduction band edge $(\mathrm{CB})$ than Ce-Ti and Ce-Ti having a lower valence band edge (VB) than Cf (Abdel-galil et al. 2014). As a result, some of the excited electrons in the $\mathrm{CB}$ of $\mathrm{Cf}$ migrate to the $\mathrm{CB}$ of $\mathrm{Ce}-\mathrm{Ti}$, that has lower energy, while some of the photogenerated holes in the VB of Ce-Ti migrate to the VB of $\mathrm{Cf}$, aiding in charge separation. Because the energy of the $\mathrm{VB}$ of $\mathrm{Cf}$ is greater than that of $\mathrm{Ce}-\mathrm{Ti}$, additional holes in the $\mathrm{VB}$ of $\mathrm{Cf}$ were produced as a result of electron transfer to the $\mathrm{VB}$ of Ce-Ti. The electrons transferred from Cf to the VB of Ce-Ti diminish the quantity of holes in $\mathrm{Ce}$ - Ti. This decreases the recombination rate and increases charge separation in the composite's $\mathrm{VB}$ and $\mathrm{CB}$, which is necessary to increase photocatalytic activity; this is an advantage of employing a linked system. Additionally, the optical band gap changes from indirect to direct when various molar ratios of $\mathrm{Ce}$-Ti to $\mathrm{Cf}$ are added, owing to the increase in $\mathrm{TiO}_{2}$ concentration. This phenomenon is caused by the transition from an amorphous to a nanocrystalline structure.

Furthermore, $\mathrm{E}_{\text {opt }}$ (optical band gap) decreases with increasing $\mathrm{TiO}_{2}$ content (Ali et al. 2019). This is highlighted by the fact that the bandgap of semiconductors is particle sizedependent (Reddy et al. 2001). The bandgap narrows as particle size increases, and the absorption edge shifts toward lower energy as particle size increases. This effect fits with the rise of crystallinity with the rise of the Ce-Timolar ratio; MB was also excited under sunlight irradiation to $\mathrm{MB}^{*}$, followed by photoinduced electron transfer from $\mathrm{MB} *$ to $\mathrm{CB}$ of $\mathrm{Ce}-\mathrm{Ti}$, that react with adsorbed species, often $\mathrm{O}_{2}$, to generate reactive superoxide radical anion. As the $\mathrm{CB}$ of $\mathrm{Ce}-\mathrm{Ti}$ and $\mathrm{Cf}$ lies above the reduction potential of $\mathrm{O}_{2} / \mathrm{O}_{2}{ }^{{ }^{-}}$(superoxide radical anion), $\mathrm{O}_{2}^{-}$wascreated by combining electrons from $\mathrm{CB}$ with the dissolved oxygen. The reaction of holes with $\mathrm{H}_{2} \mathrm{O}$ forms the hydroxyl radicals $(\mathrm{OH} \cdot)$, the hydroxyl radicals effectively decompose the organic pollutant MB. On the basis of the experimental results and comments above, a photocatalytic degradation mechanism for MB and MO dyes on the 0.5 $\mathrm{Ce}-\mathrm{Ti} / \mathrm{Cf}$ NFs composite catalyst may be postulated, as detailed in equations (1628)(Chatterjee et al. 2019).

$\mathrm{Cf}+h v \rightarrow\left(\mathrm{h}^{+}{ }_{\mathrm{vB}}+\mathrm{e}^{-} \mathrm{CB}\right) \mathrm{Cf}$ 
$721 \quad\left(\mathbf{e}^{-}{ }_{\mathrm{CB}}\right) \mathrm{Ce}-\mathrm{Ti}+\mathrm{O}_{2} \rightarrow \mathrm{O}_{2}{ }^{\bullet-(18)}$

$722 \mathrm{H}_{2} \mathrm{O}+\mathrm{O}_{2} \bullet^{-} \rightarrow{ }^{\bullet} \mathrm{OOH}+\mathrm{OH}^{-}(19)$

$723 \cdot \bullet \mathrm{OOH}+\mathrm{H}_{2} \mathrm{O} \rightarrow{ }^{\bullet} \mathrm{OH}+\mathrm{H}_{2} \mathrm{O}_{2}(20)$

$724 \quad \mathrm{H}_{2} \mathrm{O}_{2}+\left(\mathrm{e}^{-}\right) \mathrm{Ce}-\mathrm{Ti} \rightarrow{ }^{\bullet} \mathrm{OH}+\mathrm{OH}^{-}(21)$

$725 \quad \mathbf{H}_{2} \mathrm{O}_{2}+\left(h^{+}\right.$VB $) \mathbf{C f} \rightarrow \mathbf{O O H}+\mathbf{H}^{+}(\mathbf{2 2})$

$726 \quad \mathrm{H}_{2} \mathrm{O}_{2}+{ }^{\bullet} \mathrm{OOH} \rightarrow{ }^{\bullet} \mathrm{OH}+\mathrm{H}_{2} \mathrm{O}+\mathrm{O}_{2}(23)$

$727 \quad$ Dye $+\boldsymbol{h} v \rightarrow$ Dye $\bullet(24)$

728 Dye $\rightarrow$ Dye $^{+}+\left(\mathbf{e}^{-}{ }_{\text {Cв }}\right) \mathrm{Ce}-\mathrm{Ti} / \mathrm{Cf}$

729 Dye $^{\bullet}+\left(h^{+}\right.$Vв $) \mathbf{C f} \rightarrow$ Dye $^{+}$

$730 \quad\left(\mathrm{e}^{-} \mathrm{CB}\right) \mathrm{Ce}-\mathrm{Ti} / \mathrm{Cf}+\mathrm{O}_{2} \rightarrow \mathrm{O}^{\bullet}{ }_{2}^{-}(27)$

$731 \cdot \mathrm{OH}+\mathbf{O}_{2}{ }^{-}+\mathrm{Dye}^{+} \rightarrow$ Colorless degraded products

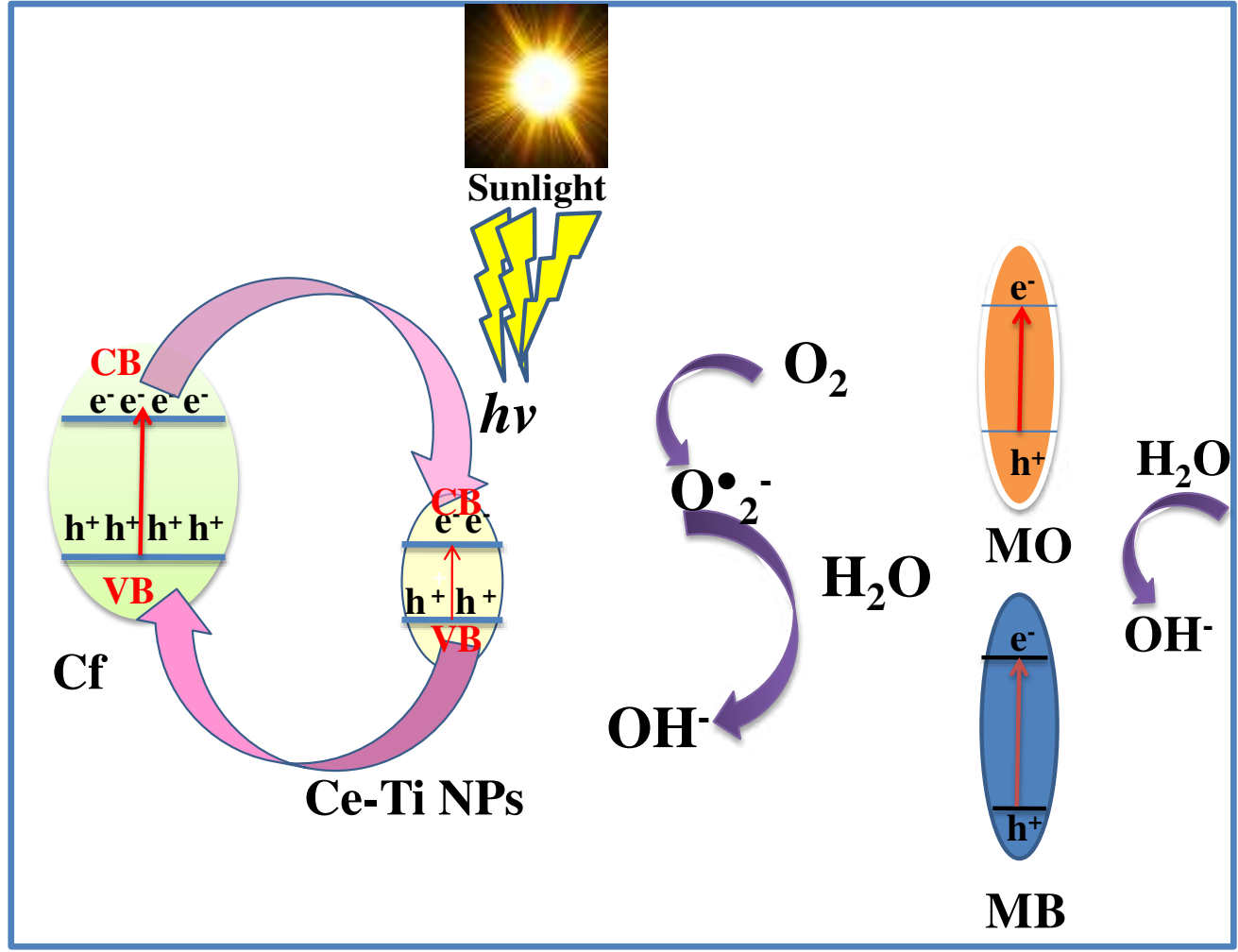

Fig.9. Proposed mechanism of $\mathrm{Ce}$-Ti/Cf nanocompositr photocatalysis for the 
3.4.Applications of sunlight energy for real wastewater treatment using $0.1 \mathrm{Ce}-\mathrm{Ti} / \mathrm{Cf}, 0.3$ $\mathrm{Ce}-\mathrm{Ti} / \mathrm{Cf}$, and $0.5 \mathrm{Ce}-\mathrm{Ti} / \mathrm{Cf}$ nanocomposite materials

Highly active (0.1 Ce-Ti/Cf, $0.3 \mathrm{Ce}-\mathrm{Ti} / \mathrm{Cf}$, and $0.5 \mathrm{Ce}-\mathrm{Ti} / \mathrm{Cf})$ nanocomposite materials were applied to degrade real textile factory wastewater (RWW). The results were collected in Table 5.The COD value of RWW following photocatalytic treatment with green-produced nanocomposite materials was determined in this work using the open reflux method (Method no. 5220B) (APHA 2012). The COD result for untreated RWW (control) was $1200 \mathrm{mgL}^{-1}$, which was significantly above than the allowed limit $\left(120 \mathrm{mgL}^{-1}\right)$. RWW's high COD value could be a result of its high organic loading and recalcitrant organic contaminants. RWW with a high COD value disrupts the ecological functioning of receiving water bodies, affecting aquatic life (Goutam et al. 2018). Nevertheless, theelimination in COD was obtained after the sunlight photocatalytic treatment of RWW with green synthesized nanocomposite materials, and the removal efficiency was $56.6,64.1$, and $90.8 \%$ for $0.1 \mathrm{Ce}-\mathrm{Ti} / \mathrm{Cf}, 0.3 \mathrm{Ce}-\mathrm{Ti} / \mathrm{Cf}$, and 0.5 Ce-Ti/Cf nanocomposite materials, respectively. The results of photodegradation are illustrated in (Table 5), and the percentage removal of COD from RWW was measuredas per(equation 2).

Table 5. Physico-chemical characteristics of treated real wastewater.

\begin{tabular}{|c|c|c|c|c|}
\hline \multirow{2}{*}{$\begin{array}{l}\text { Analytical } \\
\text { parameter }\end{array}$} & \multirow{2}{*}{$\begin{array}{c}\text { water samples } \\
\text { results } \\
\text { (wastewater(mg/l)) }\end{array}$} & \multicolumn{3}{|c|}{ Product water results } \\
\hline & & $\begin{array}{c}0.1 \mathrm{Ce}-\mathrm{Ti} / \mathrm{Cf} \\
(\mathrm{mg} / \mathrm{l})\end{array}$ & $\begin{array}{c}\text { 0.3Ce-Ti/Cf } \\
(\mathrm{mg} / \mathrm{l})\end{array}$ & $\begin{array}{c}\text { 0.5Ce-Ti/Cf } \\
(\mathrm{mg} / \mathrm{l})\end{array}$ \\
\hline TDS & 5457.52 & 1575.37 & 912.82 & 662.61 \\
\hline $\mathbf{P H}$ & 7.80 & 7.60 & 7.50 & 7.00 \\
\hline COD & 1200 & 520 & 430 & 110 \\
\hline Phenol & 5.5 & 0.89 & 0.47 & 0.27 \\
\hline MO & 10.7 & 2.28 & 1.76 & 1.02 \\
\hline MB & 2.75 & 0.00 & 0.00 & 0.00 \\
\hline Cango-red & 30.1 & 4.80 & 3.60 & 2.30 \\
\hline Malachite green & 7.29 & 0.4 & 0.4 & 0.3 \\
\hline Safranin & 8.68 & 0.48 & 0.45 & 0.42 \\
\hline $\mathrm{SO}_{4}$ & 48.27 & 19.14 & 18.69 & 15.6 \\
\hline Al & 1.5 & 1.1 & 0.3 & 0.17 \\
\hline $\mathbf{B a}$ & 0.31 & 0.03 & 0.02 & 0.015 \\
\hline $\mathbf{C u}$ & 0.42 & 0.14 & 0.12 & 0.12 \\
\hline $\mathbf{S i}$ & 3.3 & 2.3 & 2.2 & 1.2 \\
\hline $\mathrm{Sr}$ & 0.1 & 0.002 & 0.002 & 0.001 \\
\hline
\end{tabular}

The statistical analysis results are shown in Tables 6 and 7. The sum of mean squares, pvalues, and F-values, are all common aspects of ANOVA. These values indicate whether or not the model is statistically valid. As shown in the tables, the F-values were more than the p-values for each term in the model for all nanocomposite materials, suggesting the 
relevance of each interaction term. The F-value probability happening because of noise was

7590.01 percent in each case.Furthermore, the p-values for all model terms were less than 0.05 ,

760 which presented the significance of these model terms (COD, phenols, MB, MO, and

761 sulfate) and can therefore be generalized to a broader range of interest for degradation in the

762 real textile wastewater (RWW) sample against $0.1 \mathrm{Ce}-\mathrm{Ti} / \mathrm{Cf}, 0.3 \mathrm{Ce}-\mathrm{Ti} / \mathrm{Cf}$ and $0.5 \mathrm{Ce}-\mathrm{Ti} / \mathrm{Cf}$

763 nanocomposite materials.

764 Table 6.Analysis of variance (ANOVA) for fit of degradation efficiency of COD, phenol, $765 \mathrm{MO}, \mathrm{MB}$ and $\mathrm{SO}_{4}$ by $0.1 \mathrm{Ce}-\mathrm{Ti} / \mathrm{Cf}, \mathrm{O} .3 \mathrm{Ce}-\mathrm{Ti} / \mathrm{Cf}$ and $0.5 \mathrm{Ce}-\mathrm{Ti} / \mathrm{Cf}$ nanocomposite 766 materials.

767

\begin{tabular}{|c|c|c|c|c|c|c|c|}
\hline \multicolumn{8}{|c|}{ ANOVA } \\
\hline & & $\begin{array}{l}\text { Sum of } \\
\text { Squares }\end{array}$ & Dif. & $\begin{array}{l}\text { Mean } \\
\text { Square }\end{array}$ & $\mathrm{F}$ & Sig. & \\
\hline \multirow[t]{3}{*}{ COD } & Between Groups & 1954.182 & 2 & 977.091 & 47966.296 & .000 & Significant \\
\hline & Within Groups & .122 & 6 & .020 & & & \\
\hline & Total & 1954.305 & 8 & & & & \\
\hline \multirow[t]{3}{*}{ Phenol } & Between Groups & 201.492 & 2 & 100.746 & 14304.078 & .000 & \\
\hline & Within Groups & .042 & 6 & .007 & & & \\
\hline & Total & 201.534 & 8 & & & & \\
\hline \multirow[t]{3}{*}{ MO } & Between Groups & 208.127 & 2 & 104.063 & 9361.538 & .000 & \\
\hline & Within Groups & .067 & 6 & .011 & & & \\
\hline & Total & 208.194 & 8 & & & & \\
\hline \multirow[t]{3}{*}{ MB } & Between Groups & 1.870 & 2 & .935 & 9349.000 & .000 & \\
\hline & Within Groups & .001 & 6 & .000 & & & \\
\hline & Total & 1.870 & 8 & & & & \\
\hline \multirow[t]{3}{*}{$\mathrm{SO}_{4}$} & Between Groups & 94.527 & 2 & 47.264 & 3212.174 & .000 & \\
\hline & Within Groups & .088 & 6 & .015 & & & \\
\hline & Total & 94.615 & 8 & & & & \\
\hline
\end{tabular}

768

769

770

771

772

773 
778 Table 7. LSD of different 0.1 Ce-Ti /Cf, $0.3 \mathrm{Ce}$-Ti /Cf and 0.5 Ce-Ti /Cf nanocomposite 779 materials which applied on the real wastewater.

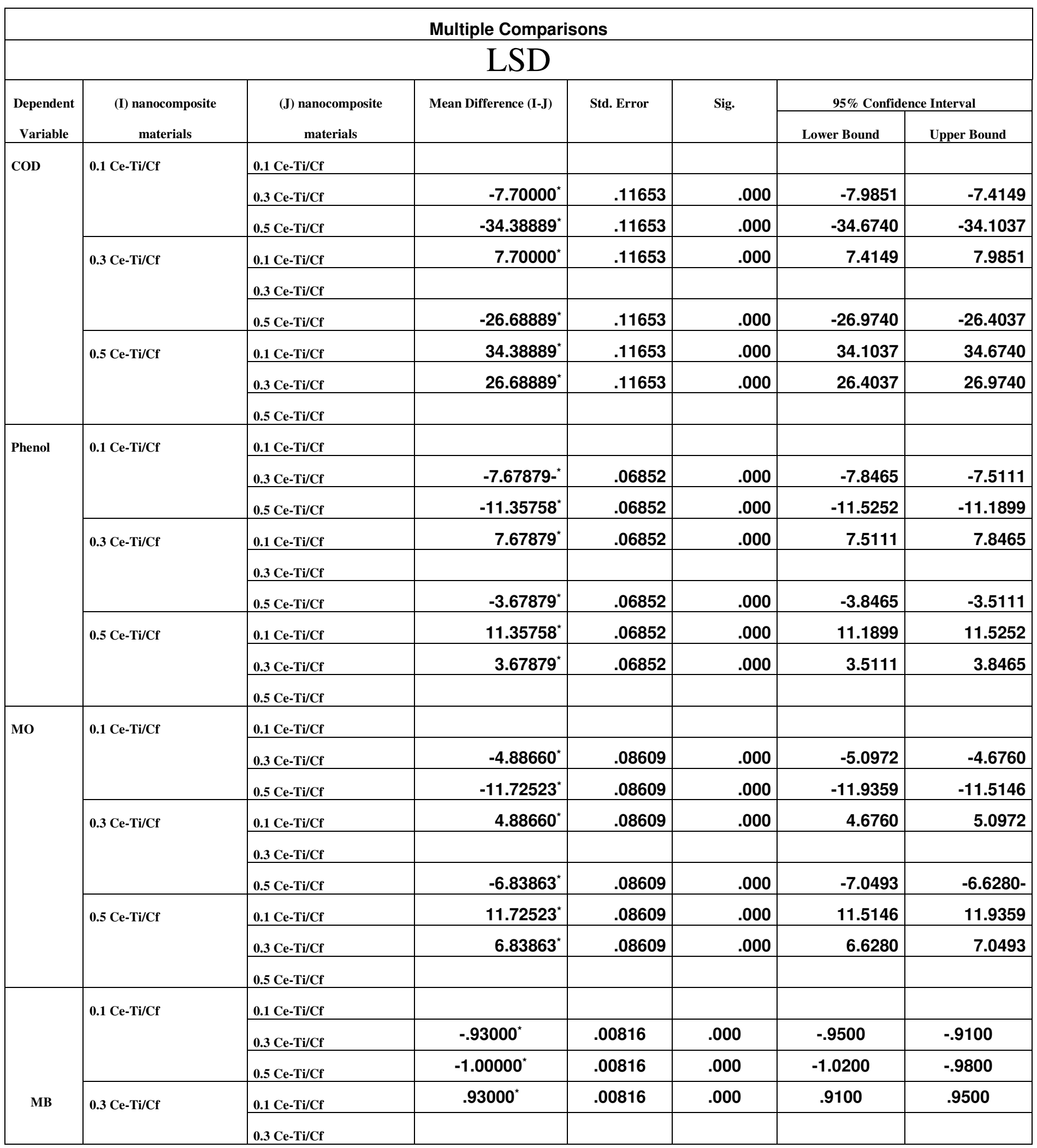




\begin{tabular}{|c|c|c|c|c|c|c|c|}
\hline & & $0.5 \mathrm{Ce}-\mathrm{Ti} / \mathrm{Cf}$ & $-.07000^{*}$ & .00816 & .000 & -.0900 & -.0500 \\
\hline & \multirow[t]{3}{*}{$0.5 \mathrm{Ce}-\mathrm{Ti} / \mathrm{Cf}$} & $0.1 \mathrm{Ce}-\mathrm{Ti} / \mathrm{Cf}$ & $1.00000^{*}$ & .00816 & .000 & .9800 & 1.0200 \\
\hline & & $0.3 \mathrm{Ce}-\mathrm{T} \mathrm{T} / \mathrm{Cf}$ & $.07000^{*}$ & .00816 & .000 & .0500 & .0900 \\
\hline & & $0.5 \mathrm{Ce}-\mathrm{Ti} / \mathrm{Cf}$ & & & & & \\
\hline \multirow[t]{9}{*}{$\mathrm{SO}_{4}$} & \multirow[t]{3}{*}{$0.1 \mathrm{Ce}-\mathrm{Ti} / \mathrm{Cf}$} & $0.1 \mathrm{Ce}-\mathrm{Ti} / \mathrm{Cf}$ & & & & & \\
\hline & & $0.3 \mathrm{Ce}-\mathrm{T} / \mathrm{Cf}$ & $-.97742^{*}$ & .09904 & .000 & -1.2198 & -.7351 \\
\hline & & $0.5 \mathrm{Ce}-\mathrm{T} \mathrm{T} / \mathrm{Cf}$ & $-7.31125^{\star}$ & .09904 & .000 & -7.5536 & -7.0689 \\
\hline & \multirow[t]{3}{*}{$0.3 \mathrm{Ce}-\mathrm{Ti} / \mathrm{Cf}$} & $0.1 \mathrm{Ce}-\mathrm{Ti} / \mathrm{Cf}$ & $.97742^{*}$ & .09904 & .000 & .7351 & 1.2198 \\
\hline & & $0.3 \mathrm{Ce}-\mathrm{Ti} / \mathrm{Cf}$ & & & & & \\
\hline & & $0.5 \mathrm{Ce}-\mathrm{Ti} / \mathrm{Cf}$ & $-6.33383^{*}$ & .09904 & .000 & -6.5762 & -6.0915 \\
\hline & \multirow[t]{3}{*}{$0.5 \mathrm{Ce}-\mathrm{Ti} / \mathrm{Cf}$} & $0.1 \mathrm{Ce}-\mathrm{Ti} / \mathrm{Cf}$ & $7.31125^{\star}$ & .09904 & .000 & 7.0689 & 7.5536 \\
\hline & & $0.3 \mathrm{Ce}-\mathrm{Ti} / \mathrm{Cf}$ & $6.33383^{*}$ & .09904 & .000 & 6.0915 & 6.5762 \\
\hline & & $0.5 \mathrm{Ce}-\mathrm{T} / \mathrm{Cf}$ & & & & & \\
\hline
\end{tabular}

780

781 The degradation efficiency achievements of $0.1 \mathrm{Ce}-\mathrm{Ti} / \mathrm{Cf}, 0.3 \mathrm{Ce}-\mathrm{Ti} / \mathrm{Cf}$, and $0.5 \mathrm{Ce}-\mathrm{Ti} / \mathrm{Cf}$

782 nanocomposite materials towards $\mathrm{MB}$ and $\mathrm{MO}$ were compared to other reported functional

783 fabrics as exposed in Table 8. 0.5 Ce-Ti/Cf nanocomposite materials showed better than

784 other reported catalysts. So, an effective degradation process and ease of preparation of 0.5

785 Ce-Tinanoparticles allow $0.5 \mathrm{Ce}$-Ti/Cf nanocomposite photocatalyst to be a promising

786 photocatalyst utilized in treating different wastewater in Egypt.

787 Table 8. Examples of photocatalytic materials for degradation of MB and MO in recent 788 years.

\begin{tabular}{|c|c|c|c|}
\hline Catalyst Type & Pollutant & Performance & References \\
\hline $\mathrm{Ag} / \mathrm{ZnO}$ cotton fabric & $\mathrm{MB}, 20 \mathrm{mg} \mathrm{L}^{-1}, 40 \mathrm{~mL}$ & $120 \mathrm{~min}, 90 \%$, UV-vis & (Ibanescu et al. 2014) \\
\hline $\mathrm{GO} / \mathrm{TiO}_{2}$ cotton fabric & $\mathrm{MB}, 10 \mathrm{mg} \mathrm{L}^{-1}, 100 \mathrm{~mL}$ & 4 days, $90 \%$, visible & (Karimi et al. 2016) \\
\hline $\mathrm{TiO}_{2}$ cotton fabric & $\mathrm{MB}, 10 \mathrm{mg} \mathrm{L}^{-1}, 100 \mathrm{~mL}$ & $14 \mathrm{~h}, 90 \%, \mathrm{UV}-\mathrm{vis}$ & (Cheng et al. 2018) \\
\hline $\begin{array}{c}\mathrm{Ag} / \mathrm{AgCl} / \mathrm{ZIF}-8 / \mathrm{TiO}_{2} \\
\text { cotton fabric }\end{array}$ & $\mathrm{MB}, 20 \mathrm{mg} \mathrm{L}^{-1}, 50 \mathrm{~mL}$ & $105 \mathrm{~min}, 98.5 \%$, visible & (Guan et al. 2019) \\
\hline $\begin{array}{l}\text { Ag@AgCl-reinforced } \\
\text { cellulose composites }\end{array}$ & $\mathrm{MB}, 15 \mathrm{mg} \mathrm{L}^{-1}, 50 \mathrm{~mL}$ & 60min, 99\%, UV-vis & (Dong et al. 2021) \\
\hline 0.1Ce-Ti/Cf & $\mathrm{MB}, 100 \mathrm{mg} \mathrm{L}^{-1}, 10 \mathrm{~mL}$ & $120 \mathrm{~min}, 91.8 \%$, sunlight & This work \\
\hline $0.3 \mathrm{Ce}-\mathrm{Ti} / \mathrm{Cf}$ & $\mathrm{MB}, 100 \mathrm{mg} \mathrm{L}^{-1}, 10 \mathrm{~mL}$ & $120 \mathrm{~min}, 92.3 \%$, sunlight & This work \\
\hline $0.5 \mathrm{Ce}-\mathrm{Ti} / \mathrm{Cf}$ & $\mathrm{MB}, 100 \mathrm{mg} \mathrm{L}^{-1}, 10 \mathrm{~mL}$ & $120 \mathrm{~min}, 94 \%$, sunlight & This work \\
\hline C-T/CA fiber & $\mathrm{MO}, 40 \mathrm{mgL}^{-1}, 20 \mathrm{ml}$ & 60min, 98\%, UV-vis & (Shi et al. 2019) \\
\hline $\mathrm{CA} / \mathrm{ZnO}-0.4$ & $\mathrm{MO}, 20 \mathrm{mgL}^{-1}, 100 \mathrm{ml}$ & 90min, $94.71 \%$, UV-vis & (Hasanpour et al. 2021) \\
\hline $\begin{array}{c}\mathrm{H}_{4} \mathrm{SiW}_{12} \mathrm{O}_{40} \\
\left(\mathrm{SiW}_{12}\right) / \text { cellulose acetate } \\
(\mathrm{CA})\end{array}$ & $\mathrm{MO}, 10 \mathrm{mgL}^{-1}, 100 \mathrm{ml}$ & 120min, 94.6\%, UV-vis & (Li et al. 2017) \\
\hline $\mathrm{TiO}_{2}$ templated by NFC & $\mathrm{MO}, 5 \mathrm{mgL}^{-1}, 100 \mathrm{ml}$ & $120 \mathrm{~min}, 100 \%$, UV-vis & (Xiao et al. 2017) \\
\hline $\mathrm{BC} / \mathrm{PDA} / \mathrm{TiO}_{2}$ fabric & $\mathrm{MO}, 20 \mathrm{mgL}^{-1}, 20 \mathrm{ml}$ & 30min, 95.1\%, UV-vis & (Yang et al. 2020) \\
\hline $\mathrm{TiO}_{2} /$ cellulose fabric & $\mathrm{MO}, 30 \mathrm{mgL}^{-1}, 25 \mathrm{ml}$ & $100 \mathrm{~min}, 99.5 \%$, UV-vis & (Chu et al. 2019) \\
\hline 0.1Ce-Ti/Cf & $\mathrm{MO}, 100 \mathrm{mg} \mathrm{L}^{-1}, 10 \mathrm{~mL}$ & $60 \mathrm{~min}, 97 \%$, sunlight & This work \\
\hline $0.3 \mathrm{Ce}-\mathrm{Ti} / \mathrm{Cf}$ & $\mathrm{MO}, 100 \mathrm{mg} \mathrm{L}^{-1}, 10 \mathrm{~mL}$ & $60 \mathrm{~min}, 98.5 \%$, sunlight & This work \\
\hline $0.5 \mathrm{Ce}-\mathrm{Ti} / \mathrm{Cf}$ & $\mathrm{MO}, 100 \mathrm{mg} \mathrm{L}^{-1}, 10 \mathrm{~mL}$ & 60 min, $98.9 \%$, sunlight & This work \\
\hline
\end{tabular}


In this work, $0.1 \mathrm{Ce}-\mathrm{Ti} / \mathrm{Cf}, 0.3 \mathrm{Ce}-\mathrm{Ti} / \mathrm{Cf}$, and $0.5 \mathrm{Ce}-\mathrm{Ti} / \mathrm{Cf}$ nanocomposite as a highly efficient photocatalyst for degradation of organic dyes have been successfully developed for the first time by using the green synthesis technique. A combination of two semiconductors $\left(\mathrm{CeO}_{2}\right.$ and $\left.\mathrm{TiO}_{2}\right)$ could induce mutual properties that would improve the activity of the hybrid nanocomposites compared to the individual materials ( $\mathrm{Cf}$ and $\mathrm{CeO}_{2} \mathrm{NPs}$ ). The fabricated nanocomposites $(0.1 \mathrm{Ce}-\mathrm{Ti} / \mathrm{Cf}, 0.3 \mathrm{Ce}-\mathrm{Ti} / \mathrm{Cf}$, and $0.5 \mathrm{Ce}-\mathrm{Ti} / \mathrm{Cf})$ were described by FTIR, SEM, XRD, and elemental analysis measurement, respectively, to obtain their chemical and morphological structures. Also, the photodegradation efficiency of methylene blue (MB) and methyl orange (MO) dyes demonstrated that the photocatalytic activity raise with a rise in the Ce-Ti molar ratio as observed in $0.5 \mathrm{Ce}-\mathrm{Ti} / \mathrm{Cf}$. The composites' effective photocatalytic activity with sunlight is owing to a synergistic effect between $\mathrm{Cf}$ and Ce-Ti NPs caused by a significant photogenerated carrier separation in the composites. Overall, the findings indicate that the addition of hydrogen peroxide could accelerate the organic molecule photodegradation with Ce-Ti when exposed to sunshine.Eventually, the conclusions of the current work participate in enhancing photodegradation purposes for the production of lowcost water in polluted provinces likeoxidation and industrial bonds), wherever water pollution is generally a serial with the rising problem.

Author contribution

Conceptualization: Yousra H. Kotp

812 Methodology: Yousra H. Kotp

813 Data curation: Yousra H. Kotp

814 Formal analysis: Yousra H. Kotp

815 Supervision: Yousra H. Kotp

816 Writing —original draft: Yousra H. Kotp

817 Writing — review and editing: Yousra H. Kotp

Funding : There is no financial support for funding this research 
820 Data Availability : Research data can be obtained from the corresponding author through

821 email.

822 Declarations Ethics approval and consent to participate: Not applicable.

823 Consent for publication: Not applicable.

824 Competing interests: The author declare no competing interests.

\section{5. References}

826 .Langan P, Nishiyama Y, Chanzy H (2021) X-ray structure of mercerized cellulose IIat $1 \AA$ 827 resolution. Biomacromolecules, 2: 410-416.https://doi.org/10.1021/bm005612q 828 Abdeldaiem MH, Hoda GM (2014) Evaluation of antioxidant activity of ethanolic extract 829 from irradiated sunflower (Helianthus Annuus L.) seeds hull. Evaluation, 4:30-37.

830 Abdel-Galil A, Ali HE, Atta A et al (2014) Influence of nanostructured TiO2 additives on 831 some physical characteristics of carboxymethyl cellulose (CMC). Journal of Radiation 832 Research and Applied Sciences, 7:36-43. https://doi.org/10.1016/j.jrras.2013.11.004 AdarakattiPS, Gangaiah V, Siddaramanna A (2018) Mesoporous CeO2 nanoparticlesmodified Glassy carbon electrode for individual and simultaneousdetermination of $\mathrm{Cu}(\mathrm{II})$ and $\mathrm{Hg}(\mathrm{II})$ : application to environmental samples.Mater. Sci. Semicond. Process. 84: 157-166.https://doi.org/10.1016/j.mssp.2018.05.010

AgarwalC, Aggrawal S, Dutt D et al (2018) Cerium oxide immobilized paper matrices for bactericidal application. Materials Science and Engineering: B, 232:17.https://doi.org/10.1016/j.mseb.2018.10.008

Aksu Z (2005) Application of biosorption for the removal of organic pollutants: a review. Process biochemistry, 40: 997-1026.https://doi.org/10.1016/j.procbio.2004.04.008

Alabi FM, Lajide L, Ajayi OO et al (2020) Synthesis and characterization of carboxymethyl cellulose from Musa paradisiaca and Tithoniadiversifolia. African Journal of Pure and

\section{Applied Chemistry, 14: 9-23.}

845 AliAA, El-Sayed SR , Shama SA et al (2020) Fabrication and characterization of cerium oxide nanoparticles for the removal of naphthol green $B$ dye. DESALINATION AND WATER TREATMENT, 204: 124-135.https://doi.org/10.1080/19443994.2014.954004 
Ali IM, Nassar MY, Kotp YH et al (2019) Cylindrical-design, dehydration, and sorption properties of easily synthesized magnesium phosphosilicatenanopowder. Particulate Science and Technology, 37:207-219. https://doi.org/10.1080/02726351.2017.1362607

AlvaroM,Cojocaru

B,Ismail

AA(2010)Visible-lightphotocatalyticactivityofgold decontaminationofthechemicalwarfareagentSOMAN,Applied

Catalysis

B:Environmenta99:191-197.https://doi.org/10.1016/j.apcatb.2010.06.019

855

856

857

858

859

860

861

862

863

864

865

866

867

868

869

870

871

872

873

874

875

876

877

An T, Chen J, Nie X et al (2012) Synthesis of carbon nanotube- anatase TiO2 submicrometer-sized sphere composite photocatalyst for synergistic degradation of gaseous styrene, ACS Appl. Mater. Interf. 4 :5988-5996. https://doi.org/10.1021/am3016476

Andronic L, Duta A (2008) The influence of $\mathrm{TiO} 2$ powder and film on the photodegradationof methyl orange, Mater. Chem. Phys. 112:1078-1082. https://doi.org/10.1016/j.matchemphys.2008.06.059

APHA (American Public Health Association) (2012) Standard Method for Examination of Water and Wastewater, 22nd ed. Washington, DC.

Barakat MA, Tseng JM, Huang CP (2005) Hydrogen peroxide-assisted photocatalyticoxidation of phenolic compounds, Appl. Catal. B: Environ. 59:99-104. https://doi.org/10.1016/j.apcatb.2005.01.004

BarrioL, Zhou G, Gonzalez ID et al (2012) In situ characterization of Pt catalysts supported on ceria modified TiO2 for the WGS reaction: influence of ceria loading, Phys. Chem. Chem. Phys. 14 : 2192-2202. http://DOI: 10.1039/C1CP22509J

BiswalDR, Singh RP (2004) Characterisation of carboxymethyl cellulose and polyacrylamide graft copolymer. Carbohydrate polymers, 57:379387.https://doi.org/10.1016/j.carbpol.2004.04.020

Bonfanti VieiraG, Jos'e, M. Peterson HJ, ZanonBaldissarelli V (2018) $\mathrm{CeO}_{2} / \mathrm{TiO}_{2}$ nanostructures enhance adsorption and photocatalytic degradation of organic compounds in aqueous suspension J. Photochem. Photobiol. A: Chem. 353: 325-336. https://doi.org/10.1016/j.jphotochem.2017.11.045

BrinkerCJ, Scherer GW (1990)Sol-Gel Science, Academic Press, Inc., San Diego, CA, USA, 45:1-8. 
ByrareddyK, Uppar DS, Vyakaranahal, BS(2008) Effect ofintegrated nutrient management on sunflower hybrid (KBSH-1) seed production. Karnataka J. Agri. Sci., 21:171-175.

Capanema N S, Mansur A A, Mansur H S et al (2018) Eco-friendly and biocompatible crosslinked carboxymethylcellulose hydrogels as adsorbents for the removal of organic dye pollutants for environmental applications. Environmental technology 39: 28562872.https://doi.org/10.1080/09593330.2017.1367845

Castañeda-Contreras J, Marañón-Ruiz VF, Chiu-Zárate R et al (2012) Photocatalytic activity of erbium-doped $\mathrm{TiO}_{2}$ nanoparticles immobilized in macro-porous silica films. Materials Research Bulletin, 47: 290-295.https://doi.org/10.1016/j.materresbull.2011.11.021

Chatterjee MJ, Ahamed ST, Mitra M (2019) Visible-light influenced photocatalytic activity of polyaniline-bismuth selenide composites for the degradation of methyl orange, rhodamine B and malachite green dyes. Applied Surface Science, 470: 472-483. DOI: 10.1016/j.apsusc.2018.11.085

Chen TF, Doong RA, Lei WG (1998) Photocatalytic degradation of parathion in aqueous TiO2suspension: the effect of hydrogen peroxide and light intensity, Water Sci. Technol. 37 :187-194.

Chen X, MaoSS(2007) Titanium dioxide nanomaterials: synthesis,properties, modifications, and applications. ChemRev 107:2891-2959.https://doi.org/10.1021/cr0500535

Cheng D, He M, Ran J et al (2018) In situ reduction of TiO 2 nanoparticles on cotton fabrics through polydopamine templates for photocatalysis and UV protection. Cellulose, 25:1413-1424. http://DOI:10.1007/s10570-017-1606-1

Cheng J, ZhanC, Wu J et al (2020) Highly efficient removal of methylene blue dye from an aqueous solution using cellulose acetate nanofibrous membranes modified by polydopamine. ACS omega5: 5389-5400.https://doi.org/10.1021/acsomega.9b04425

Chiou CH, Wu CY, Juang RS (2008) Influence of operating parameters on photocatalyticdegradation of phenol in UV/TiO2 process. Chem Eng J. 139: 322-329. https://doi.org/10.1016/j.cej.2007.08.002

Chu S, Miao Y, Qian Y et al (2019) Synthesis of uniform layer of TiO2 nanoparticles coated on natural cellulose micrometer-sized fibers through a facile one-step solvothermal method. Cellulose, 26:4757-4765. 
CrumCW, Prescott JM, Christensen PJ (1992) Genetic Approaches to Increased Nutritional Value inOilseed Meal. Proceedings of the World Conference on Oil Seed Technology and Utilization. Ed. Apple WhiteT.H. pp. 334-398,AOCS Press, Champaign, IL.

DongS, Feng J, Fan M et al (2015) Recentdevelopmentsin heterogeneous photocatalytic water treatment using visible light responsivephotocatalysts: a review, RSC Adv. 5: 1461014630.DOI: 10.1039/C4RA13734E

Dong YY, Zhu YH, Ma MG et al (2021) Synthesis and characterization of Ag@ AgClreinforced cellulose composites with enhanced antibacterial and photocatalytic degradation properties. Scientific Reports, 11:1-9. https://doi.org/10.1038/s41598-021-82447-2

ElengaRG, Dirras GF, Maniongui JG (2009) On the microstructure and physical properties of untreated raffia textilisfiber. Composites Part A: Applied Science and Manufacturing, 40:418-422.https://doi.org/10.1016/j.compositesa.2009.01.001

ErokhA, Ferraria AM, Conceicao D et al (2016) Controlled growth of Cu2O nanoparticles bound to cotton fibers. Carbohydrate Polymers, 141: 229237.https://doi.org/10.1016/j.carbpol.2016.01.019

FaganR, McCormack DE, Dionysiou DD et al (2016) A review of solar andvisible light active $\mathrm{TiO} 2$ photocatalysis for treating bacteria, cyanotoxins andcontaminants of emerging concern, Mater. Sci. Semicond. Process 42 :2-14.https://doi.org/10.1016/j.mssp.2015.07.052

FahmaF, Iwamoto S, Hori N (2010) Isolation, preparation and characterization of nanofibers from oil palm empty-fruit-bunch, Cellulose 17:977-985.https://doi.org/10.1007/s10570-0109436-4

FanL, Zhou Y, Yang W, Chen G et al (2008) Electrochemical degradation of aqueous solution of Amaranth azo dye on ACF under potentiostatic model. Dyes and pigments 76: 440-446.https://doi.org/10.1016/j.dyepig.2006.09.013

FarahmandjouM, Zarinkamar M, Firoozabadi T(2016) Synthesis of Cerium Oxide (CeO2) nanoparticles using simple CO-precipitation method. Revistamexicana de física 62: 496-499.

FrenchA, Cintrón MS (2013) Cellulose polymorphy, crystallite size, and the Segal crystallinity index. Cellulose, 20: 583-588.https://doi.org/10.1007/s10570-012-9833-y 
Ge C, Xie C, Cai S (2007) Preparation and gas-sensing properties of CedopedZnO thin-film sensors by by dip-coating.

Mater Sci

Eng

B.

$137: 53-$ 58.https://doi.org/10.1016/j.mseb.2006.10.006

939 Goutam SP, Saxena G, Singh V et al (2018) Green synthesis of TiO2 nanoparticles using 940 leaf extract of Jatropha curcas L. for photocatalytic degradation of tannery wastewater. 941 Chemical Engineering Journal, 336: 386-396.http://DOI : 10.1016/j.cej.2017.12.029

942 Guan X, Lin S, Lan J (2019) Fabrication of Ag/AgCl/ZIF-8/TiO 2 decorated cotton fabric as a highly efficient photocatalyst for degradation of organic dyes under visible light. Cellulose, 26:7437-7450.http:// DOI:10.1007/s10570-019-02621-8

945 Gurung M, Adhikari BB, Gao X et al (2014)Sustainability in the metallurgical industry: chemically modified cellulose for selective biosorption of gold from mixtures of base metals in chloride media. Industrial \& engineering chemistry research 53:8565-8576. https://doi.org/10.1021/ie403203g

949 GutierrezJ, Fernandes SCM, Mondragon I 2013) Multifunctional hybrid nanopapers based 950 on bacterial cellulose and sol-gel synthesized titanium/vanadium oxide nanoparticles. 951 Cellulose, 20: 1301-1311.https://doi.org/10.1007/s10570-013-9898-2 Harraz FA, Mohamed RM, Rashad MM (2014) Magnetic nanocomposite based on titaniasilica/cobalt ferrite for photocatalytic degradation of methylene blue dye. Ceramics International, 40:375-384. https://doi.org/10.1016/j.ceramint.2013.06.012

955 Hasanpour M, Motahari S, Jing D (2021) Numerical Modeling for the Photocatalytic Degradation of Methyl Orange from Aqueous Solution using Cellulose/Zinc Oxide Hybrid Aerogel: Comparison with Experimental Data. Topics in Catalysis:1-14. totheremovalof various typesofaqueouspollutants,Catalysis Today 53:115-129. https://doi.org/10.1016/S0920-5861(99)00107-8

HospodarovaV, Singovszka E, Stevulova N(2018) Characterization of cellulosic fibers by FTIR spectroscopy for their further implementation to building materials. American Journal of Analytical Chemistry 9: 303-310.http://DOI: 10.4236/ajac.2018.96023

$\mathrm{HuH}$, Xiao W, Yuan J et al (2008) High photocatalytic activity and stability for 
nickel substrates by sol-gel processes.J. Sol-Gel Sci. Technol. 45 : $1-$ 8.https://doi.org/10.1007/s10971-007-1650-7

968

969

970

971

972

973

974

975

976

977

978

979

980

981

982

983

984

985

986

987

988

989

990

991

992

993

Ibănescu M, Musat V, Textor T (2014) Photocatalytic and antimicrobial $\mathrm{Ag} / \mathrm{ZnOnanocomposites} \mathrm{for} \mathrm{functionalization} \mathrm{of} \mathrm{textile} \mathrm{fabrics.J} \mathrm{Alloys} \mathrm{Compd} \mathrm{610(2014)}$ 244-249. https://doi.org/10.1016/j.jallcom.2014.04.138.

JawadAH, Alkarkhi, AFM, Mubarak NSA (2015) Photocatalyticdecolorization of methylene blue by an immobilized TiO2film under visible light irradiation: optimization usingresponse $\begin{array}{llll}\text { surface } & \text { methodology } & \text { (RSM). Desalin } & \text { WaterTreat.56: }\end{array}$ 172.https://doi.org/10.1080/19443994.2014.934736

Jawad AH, Mubarak NSA, Ishak MAM et al (2016) Kinetics of photocatalytic decolourization of cationic dye using porous $\mathrm{TiO} 2$ film. Journal of Taibah University for Science,. Kineticsof photocatalyticdecolourization of cationic dye usingporous $\mathrm{TiO} 2$ film. J Taibah Univ Sci. 10: 352-362.https://doi.org/10.1016/j.jtusci.2015.03.007

Karimi L, Yazdanshenas ME, Khajavi R et al (2016)Functional finishing of cotton fabrics using graphene oxide nanosheets decorated with titanium dioxide nanoparticles, The Journal of The Textile Institute, 107:1122-1134. https://doi.org/10.1080/00405000.2015.1093311.

Kedem S, Rozen D, Cohen Y et al (2009) Enhanced stability effect in composite polymeric nanofibers containing titanium dioxide and carbon nanotubes, J. Phys. Chem. C 113:1489314899. https://doi.org/10.1021/jp9007366

Khataee,AR, Movafeghi M, Torbati S et al (2012) Phyto remediation potential of duckweed (Lemna minor L.) in degradationof C.I. Acid Blue 92: artificial neural network modeling.Ecotoxicol Environ Saf. 80:291-298.https://doi.org/10.1016/j.ecoenv.2012.03.021

KongL, Gregg DG, Karatchevtseva I (2018) Role of cetyltrimethyl ammonium bromide on sol-gel preparation of porous cerium titanate photocatalyst." Journal of Sol-Gel Science and Technology 88: 202-210.https://doi.org/10.1007/s10971-018-4779-7

Kotp YH (2020) Enhancement of industrial effluents quality by using nanocomposite Mg/Al LDH ultrafiltration membranes. Journal of Inorganic and Organometallic Polymers and Materials, 30:5244-5260. https://doi.org/10.1007/s10904-020-01608-4 
994 Kotp YH (2021) High-flux TFN nanofiltration membranes incorporated with Camphor995 Al2O3 nanoparticles for brackish water desalination. Chemosphere, 265: 128999.https://doi.org/10.1016/j.chemosphere.2020.128999

997 Kotp YH. Controlled synthesis and sorption properties of magnesium silicate nanoflower 998 prepared by a surfactant-mediated method. Separation Science and Technology, 52: 657-670. 999 https://doi.org/10.1080/01496395.2016.1264425

$1000 \mathrm{Li} \mathrm{W}$, Li T, Li G, et al (2017) Electrospun H4SiW12O40/cellulose acetate composite 1001 nanofibrous membrane for photocatalytic degradation of tetracycline and methyl orange with 1002 different mechanism. Carbohydrate polymers, 168:153-162.

1003 https://doi.org/10.1016/j.carbpol.2017.03.079

1004

1005

1006

1007

1008

1009

1010

1011

1012

1013

1014

1015

1016

1017

1018

1019

1020

1021

1022

Luo S, Nguyen-Phan TD, Johnston-Peck AC et al (2015) Electronic and Geometric Structural Influence on the Photocatalytic Activity of Oxide on Oxide Nanostructures. The Journal of Physical Chemistry 119 : 2669-2679. https://doi.org/10.1021/jp511986n

LvK,Xiang Q,Yu J (2011) Effectof calcinations temperatureonmorphology and photocatalyticactivityofanatase $\mathrm{TiO}_{2}$ nanosheets withexposed $\{001\}$ facets,AppliedCatalysisB:Environmental104:275281.https://doi.org/10.1016/j.apcatb.2011.03.019

MaheswariCU, Reddy KO, Muzenda E et al (2012) Extraction and characterization of cellulose microfibrils from agricultural residue-Cocosnucifera L. Biomass and Bioenergy, 46: 555-563.

MalynychS, Luzinov I, Chumanov G (2002) Poly (vinyl pyridine) as a universal surface modifier for immobilization of nanoparticles, J. Phys. Chem. B 106 : 12801285.https://doi.org/10.1021/jp013236d

McDevittNT, Baun WL (1964) Infrared absorption study of metal oxides in the low frequency region (700-240 $\left.\mathrm{cm}^{-} \quad 1\right)$. Spectrochimica Acta 20: 799808.https://doi.org/10.1016/0371-1951(64)80079-5

Miller CM, Valentine RL (1999) Mechanism studies of surface catalyzed H2O2 decompositionand contaminant degradation in the presence of sand, Water Res. 33:28052816. https://doi.org/10.1016/S0043-1354(98)00500-4 
1023 Mills M,Hunte S (1997) Anoverviewofsemiconductorphotocatalysis,Journal of 1024 PhotochemistryandPhotobiologyA108:1-35.https://doi.org/10.1016/S1010-6030(97)00118-4

1025 MohamedRM,Harraz FA,Mkhalid IA (2012) Hydrothermalsynthesisof size1026 controllableyttriumorthovanadate(YVO4) nanoparticlesandits application 1027 inphotocatalyticdegradationofdirectbluedye,Journalof Alloys andCompounds532: 55-60. 1028 https://doi.org/10.1016/j.jallcom.2012.04.016

1029 NtwaeaborwaOM, Holloway PH (2005) Enhanced photoluminescence of $\mathrm{Ce}^{3+}$ induced by an 1030 energy transfer from $\mathrm{ZnO}$ nanoparticlesencapsulated in SiO2. Nanotechnology. 1031 16:865.https://doi.org/10.1088/0957-4484/16/6/042

1032 Nwokolo E, Sunflower (Heliauthusannus L.) In "Food and Feed from Legumes and Oil Seed" 1033 Editors, E. Nwokolo and Smartt, J.,Chapter 28, Chapman \& Hall, NY(1996).

1034 Peng N, Hu D, Zeng J et al (2016) Superabsorbent cellulose-claynanocomposite hydrogels 1035 for highly efficient removal ofdye inwater. ACS Sustainable ChemEng. 4 : 72171036 7224.https://doi.org/10.1021/acssuschemeng.6b02178

1037 Pera-Titus M,Garcona-MolinaV,Banos M $\quad$ (2004) Degradation 1038 ofchlorophenolsbymeansofadvanced oxidation a 1039 generalreview,AppliedCatalysisB:Environmental47: 219-256. 1040 https://doi.org/10.1016/j.apcatb.2003.09.010

1041 Pirhashemi M, Habibi-Yangjeh A (2017) Ultrasonic-assisted preparation of 1042 plasmonic $\mathrm{ZnO} / \mathrm{Ag} / \mathrm{Ag}_{2} \mathrm{WO}_{4} \quad$ nanocomposites with high visible-light 1043 photocatalyticperformance for degradation of organic pollutants, J. Colloid Interface Sci. 1044 491:216-229.https://doi.org/10.1016/j.jcis.2016.12.044

1045 PolettoM, Ornaghi HL, .Zattera AJ (2014) Native cellulose: structure, characterization and 1046 thermal properties. Materials 7: 6105-6119.https://doi.org/10.3390/ma7096105

1047 PuttaswamyM, Srinikethan G, Shetty V(2017) Biocomposite composed of PVAreinforced 1048 with cellulose microfibers isolated from biofuel industrial dissipate: JatrophaCurcus L. seed 1049 shell. Journal of Environmental Chemical Engineering, 5: 19901050 1997.https://doi.org/10.1016/j.jece.2017.04.004 

cellulose single fibers from native africannapier grass. Carbohydrate polymers, 188: 8591.https://doi.org/10.1016/j.carbpol.2018.01.110

1054 ReddyKO, Zhang J, Zhang J et al (2014) Preparation and properties of self-reinforced 1055 1056 cellulose composite films from Agave microfibrils using an ionic liquid.Carbohydrate Polymers, 114: 537-545.https://doi.org/10.1016/j.carbpol.2014.08.054

1057

Reddy MC, Dourish P, Pratt W (201) Coordinating Heterogeneous Work: Information and 1058 Representation in Medical Care. In: Prinz W., Jarke M., Rogers Y., Schmidt K., Wulf V. 1059 (eds) ECSCW 2001. Springer, Dordrecht. https://doi.org/10.1007/0-306-48019-0_13.

1060

Sanchez-Garcia MD,GimenezE, Lagaron JM (2008) Morphology and barrier properties of 1061 solvent cast composites of thermoplastic biopolymers and purified cellulose fibers. 1062 Carbohydrate Polymers, 71: 235-244.https://doi.org/10.1016/j.carbpol.2007.05.041

1063

SegalL, Creely JJ, Martin AE (1959) An empirical method for estimating the degree of 1064

1065 crystallinity of native cellulose using the X-Ray dif-fractometer. Textile Research Journal, 29: 786-794.https://doi.org/10.1177/004051755902901003

1066

ShaoX, Wang J, Liu Z et al (2021) Cellulose based cation-exchange fiber as filtration 1067 material for the rapid removal of methylene blue from wastewater. Cellulose, (2021)1-13.

1068 SharmaJK, Srivastava P, Ameen S(2017) Phytoconstituents assisted green synthesis of 1069 1070 cerium oxide nanoparticles for thermal decomposition and dye remediation. Materials Research Bulletin 91:98-107.https://doi.org/10.1016/j.materresbull.2017.03.034

Shi X, Zhang X, Ma L et al (2019) TiO2-doped chitosan microspheres supported on 1072 cellulose acetate fibers for adsorption and photocatalytic degradation of methyl orange. Polymers, 11:1293. https://doi.org/10.3390/polym11081293

1074 SproulWD, Graham ME, Wong MS (1997)Reactive dc magnetron sputtering of the oxides 1075 of Ti, Zr, and Hf, Surf. Coat. Technol. 89 :10-15.https://doi.org/10.1016/S02571076 8972(96)02913-1

1077 TahaFS, Wagdy SM, Hassanein MMM et al (2012) Evaluation of the biological activity of 1078 sunflower hull extracts. grasas y aceites, 63: 184-192. 
1079 Tajizadegan H, Torabi O, Heidary A et al (2015) Study of methylorange adsorption 1080 properties on $\mathrm{ZnO}-\mathrm{A} 12 \mathrm{O} 3$ nanocomposite adsorbent particles, Desalination\& Water Treatment 57:1-11. https://doi.org/10.1080/19443994.2015.1049558

1082 TouatiA, .Hammedi T, Najjar W et al (2016) Photocatalytic degradation of textile 1083 wastewater in presence of hydrogen peroxide: Effect of cerium doping titania. Journal of Industrial and Engineering Chemistry, 35:36-44.https://doi.org/10.1016/j.jiec.2015.12.008

1085

Tryk DA,FujishimaA,Honda K

K (2000)

Recenttopicsinphotoelectrochemistry:

1086 achievementsandfutureprospects,ElectrochimicaActa45:2363-

1087 2376.https://doi.org/10.1016/S0013-4686(00)00337-6

1088

Vieira GB, José HJ, Peterson $\mathrm{M}$ et al (2018)CeO2/TiO2 nanostructures enhance adsorption 1089 and photocatalytic degradation of organic compounds in aqueous suspension. Journal of 1090 Photochemistry and Photobiology A: Chemistry, 353: 325-336.

1091 https://doi.org/10.1016/j.jphotochem.2017.11.045

1092 Wang Q, Wang Y, Chen L et al (2017) Facile construction of cellulose nanocomposite 1093 1094 aerogel containing $\mathrm{TiO} 2$ nanoparticles with high content and small size and their applications. Cellulose, 24:2229-2240. http:// doi:10.1007/s10570-017-1262-5

1095

WangQ, Xie D, Chen J (2020) Superhydrophobic paper fabricated via nanostructured 1096 titanium dioxide-functionalized wood cellulose fibers. Journal of Materials Science 55: 70841097 7094.https://doi.org/10.1007/s10853-020-04489-7

1098

Woo Y S, Rafatullah M, Al-Karkhi AFM et al (2014) Removal of Terasil Red R dye by 1099 using Fenton oxidation: a statistical analysis. Desalination and Water Treatment 52: 45834591.https://doi.org/10.1080/19443994.2013.804454

1101 Wu J S, Liu C H, Chu K H et al (2008) Removal of cationic dye methyl violet 2B from water 1102 by cation exchange membranes. Journal of membrane science309: 2391103 245.https://doi.org/10.1016/j.memsci.2007.10.035

Xiao H, Li J, He B (2017) Anatase-titania templated by nanofibrillated cellulose and photocatalytic degradation for methyl orange. Journal of Inorganic and Organometallic Polymers and Materials, 27:1022-1027. https://doi.org/10.1007/s10904-017-0550-8 
Yan H, Zhang W, Kan X et al (2011) Sorption of methylene blue by carboxymethyl cellulose and reuse process in a secondary sorption, Colloids and Surfaces A: Physicochemical and Engineering Aspects 380:143-151.https://doi.org/10.1016/j.colsurfa.2011.02.045

Yang L,Chen C, Hu Y et al (2020) Three-dimensional bacterial cellulose/polydopamine/TiO2 nanocomposite membrane with enhanced adsorption and photocatalytic degradation for dyes under ultraviolet-visible irradiation. Journal of colloid and interface science, 562:21-28. https://doi.org/10.1016/j.jcis.2019.12.013

Yu J, Wang K, Xiao W et al (2014) Photocatalytic reduction of CO2 into hydrocarbonsolar fuels over g-C3N4-Pt nanocomposite photocatalysts, Phys. Chem. Chem. Phys., 16:1149211501.http:// DOI: 10.1039/C4CP00133H

Zhai L, Bai Z, Zhu Y et al (2018) Fabrication of chitosan microspheres for efficient adsorption of methyl orange. Chinese Journal of Chemical Engineering, 26: 657-666. https://doi.org/10.1016/j.cjche.2017.08.015

Zhang G, YiL, Deng $\mathrm{H}$ et al. (2014) Dyes adsorption using a synthetic carboxymethyl cellulose-acrylic acid adsorbent. Journal of Environmental Sciences 26: 12031211.https://doi.org/10.1016/S1001-0742(13)60513-6

ZhangJ, Liu W, Wang P(2013) Photocatalytic behavior of cellulose-based paper with TiO2 loaded on carbon fibers. Journal of Environmental Chemical Engineering, 1:175182.https://doi.org/10.1016/j.jece.2013.04.022

ZhangQ, Griffin GL 1995) Gas-phase kinetics for TiO2 CVD: hot-wall reactor results. Thin Solid Films 263 : 65-71. https://doi.org/10.1016/0040-6090(95)06580-6

Zhang W, Dong Y, Zhou Y (2018) Role of cetyltrimethyl ammonium bromide on sol-gel preparation of porous cerium titanate photocatalyst. Journal of Sol-Gel Science and Technology, 88:202-210. https://doi.org/10.1007/s10971-018-4779-7

ZhangY, Gu D, Zhu L et al (2017) Highly ordered $\mathrm{Fe}^{3+} / \mathrm{TiO}_{2}$ nanotube arrays for efficient photocataltyic degradation of nitrobenzene. Applied Surface Science, 420:896904.https://doi.org/10.1016/j.apsusc.2017.05.213

ZhaoH, Kwak JH, Zhang ZC (2007) Studying cellulose fiber structure by SEM, XRD, NMR and acid hydrolysis. CarbohydratePolymers, 68: 235241.https://doi.org/10.1016/j.carbpol.2006.12.013 
1137 ZhuS, Zhang D, Zhang X et al (2009) Unlocking the door to highly efficient Ag-based 1138 nanoparticles catalysts for $\mathrm{NaBH}$ 4-assisted nitrophenol reduction. Micropor. Mesopor. 1139 Mater. 126 : 20-25.https://doi.org/10.1007/s12274-019-2441-5 


\section{Supplementary Files}

This is a list of supplementary files associated with this preprint. Click to download.

- graphical.jpg 